IZA DP No. 10237

Mandatory Minimum Policy Reform and the Sentencing of Crack Cocaine Defendants: An Analysis of the Fair Sentencing Act

David Bjerk

September 2016 


\title{
Mandatory Minimum Policy Reform and the Sentencing of Crack Cocaine Defendants: An Analysis of the Fair Sentencing Act
}

\author{
David Bjerk \\ Claremont McKenna College \\ and IZA
}

Discussion Paper No. 10237

September 2016

\author{
IZA \\ P.O. Box 7240 \\ 53072 Bonn \\ Germany \\ Phone: +49-228-3894-0 \\ Fax: +49-228-3894-180 \\ E-mail: iza@iza.org
}

Any opinions expressed here are those of the author(s) and not those of IZA. Research published in this series may include views on policy, but the institute itself takes no institutional policy positions. The IZA research network is committed to the IZA Guiding Principles of Research Integrity.

The Institute for the Study of Labor (IZA) in Bonn is a local and virtual international research center and a place of communication between science, politics and business. IZA is an independent nonprofit organization supported by Deutsche Post Foundation. The center is associated with the University of Bonn and offers a stimulating research environment through its international network, workshops and conferences, data service, project support, research visits and doctoral program. IZA engages in (i) original and internationally competitive research in all fields of labor economics, (ii) development of policy concepts, and (iii) dissemination of research results and concepts to the interested public.

IZA Discussion Papers often represent preliminary work and are circulated to encourage discussion. Citation of such a paper should account for its provisional character. A revised version may be available directly from the author. 
IZA Discussion Paper No. 10237

September 2016

\section{ABSTRACT}

\section{Mandatory Minimum Policy Reform and the Sentencing of Crack Cocaine Defendants: An Analysis of the Fair Sentencing Act}

The Fair Sentencing Act of 2010 (FSA) affected the U.S. federal mandatory minimum sentencing laws for to crack cocaine offenders, and represented the first Congressional reform of sentencing laws in over 20 years. A primary goal of this legislation was to lessen the harshness of sentences for crack cocaine offenders and decrease the sentencing gap between crack defendants and powder cocaine defendants. While both the mean sentence length for crack offenders fell following the implementation of the FSA, these changes appear to primarily reflect the continuation of on-going sentencing trends that were initiated by a variety of non- Congressional reforms to federal sentencing policy that commenced around 2007. However, the FSA appears to have been helpful in allowing these trends to continue past 2010.

JEL Classification: K40

Keywords: mandatory minimums, fair sentencing act, crack cocaine, powder cocaine, sentencing guidelines

Corresponding author:

David Bjerk

Department of Economics

Claremont McKenna College

500 East Ninth Street

Claremont CA 91711

USA

E-mail: david.bjerk@cmc.edu

\footnotetext{
* Forthcoming in: Journal of Empirical Legal Studies. Special thanks to JJ Prescott, Eric Helland, Hani Mansour and other members of the University of Colorado-Denver for their valuable input on this project.
} 


\section{Introduction}

The Anti-Drug Abuse Act of 1986 implemented mandatory minimum sentences upon conviction for trafficking in quantities of drugs exceeding specific quantity thresholds for each drug. While crack cocaine is produced from powder cocaine, and therefore is pharmacologically identical in its active ingredient, the mandatory minimum triggering quantities prescribed under the law were extremely different for the two drugs, with the ratio of powder cocaine relative to crack cocaine needed to trigger eligibility for a mandatory minimum being 100:1.

The reasons Congress initially cited for justifying the differential treatment of crack cocaine relative to powder cocaine under the mandatory minimum legislation were eventually revealed to have little merit. Moreover, the disparate treatment of crack cocaine relative to powder cocaine also became viewed as racially biased, as over 80 percent of those convicted for crack have generally been African-American, while less than 33 percent of those convicted for other drugs such as powder cocaine, methamphetamine, and marijuana have been AfricanAmerican (Vagins and McCurdy, 2006).

In response to this controversy, there developed strong bi-partisan support to lessen the disparate treatment of crack relative to powder cocaine under the mandatory minimums, which eventually led to the passage of the Fair Sentencing Act of 2010 (FSA). The primary policy change inherent in the actual FSA legislation was that the mandatory minimum triggering quantities for crack cocaine were increased roughly five-fold while holding the mandatory minimum triggering quantities for other drugs (including powder cocaine) constant. Thus, following the implementation of the FSA, the ratio of powder cocaine relative to crack cocaine needed to trigger eligibility for a mandatory minimum dropped from 100:1 to about 20:1.

Many U.S. legislators and ideological disparate groups including the Open Society Policy Center, the American Humanist Association, and the National Association of Evangelicals heralded the FSA as a major policy change that will increase the fairness of U.S. sentencing policy. Such praise might at first glance appear to be warranted, as the mean sentence for crack defendants fell by 17 months, or almost 16 percent, in the two years just after the passage of the FSA relative to the two years just before. However, the evidence presented in this paper suggests this simple observation presents a somewhat misleading picture the FSA's impact sentencing.

In particular, this paper argues that the FSA should not be viewed as a mechanism by which the US Congress pushed the US district courts into reducing sentencing for crack 
offenders (and thereby lessening the crack/powder cocaine sentencing gap), but rather as a Congressional assist to a variety of other reforms to the United States federal sentencing guidelines that have allowed federal judges and prosecutors to act on their preferences for shorter sentences for crack offenders. More specifically, the United States' Supreme Court's decisions in the Booker case and subsequent Rita, Gall, and Kimbrough cases which made the United States sentencing guidelines advisory rather than mandatory by 2007, and the United States Sentencing Commission's implementation of the Crack Amendment of 2007 which altered the U.S. sentencing guidelines for crack offenders, initiated a trend toward more leniency in sentencing of crack offenders. The subsequent adjustments to mandatory minimum triggering quantities as directed by the FSA, in conjunction with further reforms to the United States Sentencing Guidelines for crack offenders that occurred concurrently, allowed this evolution toward more lenient sentencing norms for crack offenders to continue. Therefore, in assessing whether the impact of the FSA should be considered a major policy reform, the answer appears somewhat nuanced. While the reforms to mandatory minimums inherent in the FSA appear to have done little in and of themselves to accelerate downward trends in sentencing of crack offenders and the crack/powder cocaine sentencing gap, the implementation of the FSA likely helped preclude the mandatory minimums from substantially impeding the continuance of the pre-FSA trends toward greater leniency.

\section{Background on the Fair Sentencing Act of 2010}

Crack cocaine first started to be manufactured and used in the early 1980 s as an alternative to freebasing cocaine, or heating powder cocaine and inhaling the vapors. Crack cocaine use expanded quickly, particularly in low income predominantly African-American neighborhoods (Chitwood et al. 1996). With the crack trade expanding, violence and cocainerelated deaths increased (Kerr 1986; Klein et al. 1991; Grogger and Willis 2000; Fryer et al. 2013) to the point where it was being termed an epidemic.

The issue of drug addiction and the proliferation of crack became prominent enough such that by the mid-1980s Congress passed the Anti-Drug Abuse Act of 1986. The major policy aspect of the Anti-Drug Abuse Act was mandated minimum sentences triggered by strict quantity thresholds that differed by drug. Table 1a shows the different mandatory minimums and their triggering quantities associated with different drugs and different criminal histories as 
dictated by the Anti-Drug Abuse Act. As can be seen, there are two triggering quantity thresholds for each drug, where the higher one corresponds to a higher mandatory minimum (unless the defendant has been convicted for two previous drug felonies and there was bodily injury associated with the current conviction). Notably, these mandatory minimum triggering quantities were far lower for crack cocaine than for all other major drugs. Possibly most controversially, the ratios between the mandatory minimum triggering quantities for powder cocaine relative to crack cocaine were $100: 1 .^{1}$

This disparate treatment of crack cocaine relative to powder cocaine was increasingly criticized as being racially biased, as crack cocaine defendants were far more likely to be black than white. Indeed, in the year 2000, the United States Sentencing Commission reported that over eighty percent of federal crack cocaine offenders were black, a rate far above the analogue for other drugs (U.S.S.C. 2002).

At the urging of several civil rights groups including the American Civil Liberties Union and the Sentencing Project, by the early 2000s both the United States Sentencing Commission and a bi-partisan coalition of congressmen voiced support for decreasing or even eliminating the differential treatment of crack cocaine relative to powder cocaine. Even with such support any such legislation faced opposition and numerous hurdles. The Fair Sentencing Act (FSA) was eventually introduced as a comprise plan, and signed into law August 3, 2010. The primary policy reform associated with the act was to change the mandatory minimum triggering quantities for crack cocaine. In particular, while the FSA did not fully eradicate the disparate treatment of crack cocaine relative to powder cocaine, it decreased the 100:1 ratio of mandatory minimum triggering quantities to a roughly 20:1 ratio. Table $1 \mathrm{~b}$ shows the key details associated with the FSA legislation. For crack cocaine offenders, the lower mandatory minimum triggering quantity rose from 0.005 kilograms to 0.028 kilograms, and the upper mandatory minimum triggering quantity rose from 0.05 kilograms to 0.28 kilograms. The FSA did not alter the mandatory minimum triggering quantities for other drugs.

Up to and after the implementation of the FSA, individuals and groups from across the political spectrum hailed the act as a substantial policy reform aimed to mitigate the crack cocaine/powder cocaine sentencing disparity, and in conjunction lessen the racial disparity of the

\footnotetext{
${ }^{1}$ For a good review of the background on reforming the Anti-Drug Abuse Act of 1986 see Beaver (2010), as well as Reinaman et al. (1997) and Vagins and McCurdy (2006).
} 
federal justice system. For example, on the political left, Patrick Leahy, a Democratic United States Senator, said "(a)fter more than 20 years, the Senate has finally acted on legislation to correct the crack-powder disparity and the harm to public confidence in our justice system it created." Similarly, Roy Speckhardt, executive director of the American Humanist Association, said "(t)his corrects a historical injustice within our legal system," and Nkechi Taifa, a senior policy analyst at the Open Society Policy Center, stated " $(\mathrm{t})$ his victory in drug sentencing reform is extraordinary; advocates have been fighting for nearly two decades to eliminate the egregious disparity between crack and powder cocaine. We have significantly 'cracked the disparity' with unprecedented bipartisan support and will continue the critical work to achieve a fair and just criminal justice system." These sentiments are not only relegated to the political left. For example, Galen Carey, director of government affairs at the National Association of Evangelicals, remarked " $(\mathrm{t})$ he legislation makes significant progress toward parity in criminal penalties for possession and use of crack and powder cocaine."

As will be seen in more detail below, however, in evaluating the impact of the FSA, it is important not to view the FSA in isolation, but rather in the broader context of a variety of sentencing reforms not specifically related to mandatory minimums that were occurring concurrently and even well before the implementation of the FSA. Importantly, while the FSA itself only affected the quantity cutoff thresholds for mandatory minimums for crack cocaine, the United States Sentencing Commission (USSC) responded to the FSA in November 2010 by altering the entire sentencing guideline structure for crack cocaine to make it consistent with the new mandatory minimum cutoffs. To put it another way, while the FSA itself only affected sentencing for crack offenders convicted for quantities between 0.005 kilograms and 0.028 kilograms (who now faced no mandatory minimum) and crack offenders convicted for quantities between 0.05 kilograms and 0.28 kilograms (who now faced a lower mandatory minimum), the changes to the sentencing guidelines ostensibly applied to all crack offenders.

Moreover, the whole of the USSC sentencing guidelines underwent some quite radical changes a few years prior to passage of the FSA. The guidelines are determined not by Congress, but rather by the United States Sentencing Commission, and map each quantity of each drug into an "offense severity" score, which in conjunction with a criminal history score, map into a cell in a sentencing grid that is associated with a relatively narrow sentence range. Initially, the USSC guidelines were mandatory, but in a series of United States Supreme Court decisions starting 
with the Booker decision of 2005, and maybe most notably the Kimbrough decision in late 2007, substantially weakened the role for the guidelines. In particular, the Kimbrough decision held that a judge could depart from the guidelines if he/she disagreed with the policy choices underlying the guideline sentence---most notably the disparate treatment of crack cocaine relative to powder cocaine. In other words, the guidelines changed from being mandatory to advisory. Moreover, also in late 2007, the USSC lowered the "offense severity" score for all crack cocaine offenders in the sentencing guidelines, effectively lessening the recommended guideline sentence for all crack offenders (this change to the guidelines is often referred to as the 2007 Crack Amendment). As I discuss in more detail below, these changes in the structure and force of the USSC guidelines appear to have had large implications on sentencing, particularly for crack offenders.

To my knowledge, there have been no formal analyses of the impact of the FSA on sentence lengths for crack defendants or on the sentencing gap between crack cocaine defendants and powder cocaine defendants. However, there is a diverse literature looking at mandatory minimum sentencing laws more broadly. For example, LaCasse and Payne (1999), Bjerk (2005), Ulmer, Kurlychek, and Kramer (2007), and Rehavi and Starr (2013) look at how mandatory minimums impact pre-trial bargaining. Helland and Tabarrok (2007), Shepard (2002), Marvell and Moody (2001), and Loftin, McDowall, and Weirsema (1992) examine the extent to which mandatory minimums may affect the behavior of potential criminals. Loftin, Heumann, and McDowall (1983) look at both of these issues with respect to a state mandatory minimum law for gun crimes. Somewhat relatedly, Fischman and Schanzenbach (2012) argue that mandatory minimums may have played a role in increasing racial disparities in sentencing following the U.S. Supreme Court's decisions that declared the Sentencing Guidelines to be advisory rather than mandatory. ${ }^{2}$

Studies that focus explicitly on mandatory minimums for drug crimes are fewer, but still encompass a wide spectrum of analyses. For example, Caulkins et al. (1997) conduct a cost/benefit analysis of the mandatory minimums for cocaine, Kautt and Spohn (2002) look at whether defendants of different races or genders are more or less subject to federal drug mandatory minimum sentences, and Hartley, Maddan, and Spohn (2007) look at how prosecutors

\footnotetext{
${ }^{2}$ See Tonry (1992) for a detailed discussion of many of the issues that have been highlighted regarding mandatory minimums.
} 
apply "substantial assistance" to circumvent guidelines and mandatory minimums for crack and powder cocaine cases.

Some of the most comprehensive work looking at federal mandatory minimum sentences for drug crimes has been done by the United States Sentencing Commission (USSC 2011). Using federal sentencing data from the 2010 fiscal year (a subset of the data used in the analysis below), the USSC finds that mandatory minimum eligible federal drug defendants appear to receive sentences consistent with the mandated minimums less than half of the time, primarily due to the federal "safety-valve" statute which allows defendants meeting certain criteria (notably a minimal criminal history) to avoid a mandatory minimum. The U.S.S.C. report also finds that eligible black defendants are more likely to receive a sentence consistent with the mandated sentence than white or Hispanic defendants. While the U.S.S.C. study suggests that part of the reason black defendants were more likely than defendants of other races to receive a sentence consistent with the mandatory minimum might be because they were more likely to have substantial criminal records making them ineligible for safety valve relief, they did not explicitly analyze this issue.

\section{Methodology}

The goal of the first part of this paper is the estimate the direct impact of the FSA legislation on the expected sentence length for crack offenders. The "naïve" approach would be to just compare the expected sentence for crack offenders sentenced after the FSA took effect to those sentenced prior to the FSA (i.e., 2010 and earlier), or if we let $\delta$ represent the impact of the FSA, this would correspond to $\delta=E\left[S_{\text {crack }} \mid\right.$ post-FSA $]-E\left[S_{\text {crack }} \mid\right.$ pre-FSA], where $S_{\text {crack }}$ refers to sentences for crack offenders and $\mathrm{E}[\mathrm{]}$ is the mathematical expectation operator.

However, there are a couple of key issues that will cause the naïve approach mentioned above to potentially dramatically overstate $\delta$, or overstate the direct impact of the FSA. First, there might be other trends impacting changes in expected sentence for crack offenders beyond the FSA. For example, one might be concerned that the characteristics of crack defendants are changing over time (most notably their criminal histories and/or their conviction quantities), and these compositional changes amongst crack defendants are impacting average sentence lengths for crack. Similarly, there may be other policies and reforms (such as those highlighted in the previous section) that may have been affecting sentences for crack offenders over time. Given 
the possibility of such other trends, $E\left[S_{\text {crack }} \mid\right.$ post-FSA $]-E\left[S_{\text {crack }} \mid\right.$ pre-FSA] will be a biased estimate of $\delta$, or in other words not capture just the impact of the FSA, as it will conflate the impact of the FSA with these other trends. Therefore, to assess the impact of the FSA, not only do we have to control for any changes in crack defendant characteristics over time, but also, rather than evaluate whether there was a change in expected sentences for crack offenders following the implementation of the FSA, we need to evaluate whether there was a change in the trend in the expected sentencing for crack offenders following the implementation of the FSA.

To control for changes in crack defendant characteristics and test for a break in the sentencing trend for crack offenders following the FSA, I estimate a regression of the following form for all crack defendants:

$$
S_{i}=\alpha+\beta_{1}^{*} t+\delta^{*} \text { postFSA } A_{i}+\Phi X_{i}+\eta D+\varepsilon_{i}
$$

where $S_{i}$, corresponds to the sentence given to a defendant $i, t$ is a linear monthly time trend, and $\operatorname{postFSA}_{i}$ is a dummy variable equal to one if the defendant was sentenced after the FSA became effective. To account for any changes in defendant characteristics over time, the vector $X_{i}$ includes race and gender dummies, criminal history dummies, and quantity category dummies (corresponding to the cells in USSC sentencing grid severity scores), while $D$ is a vector of district fixed-effects to control for the possibility that more lenient districts may have received a larger or smaller fraction of crack cases over time. The final term, $\varepsilon_{i}$, is the residual error term. ${ }^{3}$ The parameter of interest in equation (1) is $\delta$, which measures the extent to which there was a discrete shift in the trend of expected sentences for crack offenders in the time following the implementation of the FSA.

Given first time offenders can often avoid a mandatory minimum via the "safety-valve" designation which is only available to those with minimal criminal histories, one might think that the FSA had very heterogeneous impacts on non-first time offenders relative to first-time offenders. Therefore, I also estimate a version of equation (1) where I put in separate time-trends for first-time offenders and repeat offenders, and put in separate postFSA dummies for first-time offenders and repeat offenders.

\footnotetext{
${ }^{3} \mathrm{I}$ also use natural log of sentence length as the dependent variable as a robustness check.
} 
There is a second reason why the naïve approach discussed at the outset of this section might be a biased assessment of the FSA. Namely, as alluded to in the previous section, the changes to crack mandatory minimums inherent in the FSA were not the only changes to sentencing policy in the fall of 2010, as just after the implementation of the FSA, the USSC also altered the guidelines for all crack offenders to make them consistent with the revised mandatory minimum cutoffs specified by the FSA. This means that to the extent expected sentences for crack offenders did fall following the implementation of the FSA (at least relative to pre-FSA trends), some of this might not be due to the FSA changes to mandatory minimums, but rather due to the changes in the sentencing guidelines.

To consider this issue, I examine the degree to which expected sentences for crack offenders fell for those whose sentences should have been directly impacted by the reforms to mandatory minimums inherent in the FSA relative to those whose sentences should not have been impacted by the reforms to the mandatory minimums (but may well have been impacted by the changes to the sentencing guidelines). In particular, as discussed above, the FSA only changed the mandatory minimum sentences for crack defendants convicted for quantities between 0.005 kilograms to 0.028 kilograms and those convicted for quantities between 0.05 kilograms and 0.28 kilograms (hereafter FSA affected crack quantities). Sentences for crack defendants convicted for other quantities may have been affected by the changes to the sentencing guidelines, but should not have been impacted by the changes to mandatory minimums due to the FSA. Therefore, I look at how sentences changed for offenders convicted for FSA affected crack quantities surrounding the implementation of the FSA relative to the analogous changes in sentencing for those crack offenders convicted for quantities ostensibly unaffected by the FSA. The extent to which expected sentences changed differentially for offenders convicted for FSA affected crack quantities relative to offenders convicted for quantities unaffected by the FSA in the time surrounding the implementation of the FSA will also provide a measure of the direct impact of just the changes to the mandatory minimums as directed by the FSA, relative to other policies affecting crack sentencing.

\section{Description of the Data}

The data used for this paper come from the annual Monitoring of Federal Criminal Sentences datasets. The primary analyses that follow are based on the 2009 through 2012 
versions (though later I also look at data from versions going all the way back to 2002). These data are collected and organized by the United States Sentencing Commission, and contain information on all cases sentenced under the federal court system. These data sets contain a wealth of defendant information, including conviction charge---and for drug convictions, conviction drug type and quantity---as well as adjudication district, and demographic and criminal history category for each defendant. Moreover, sentencing information is provided.

From this data, I extract only cases where the defendant was charged with only one type of drug, where that drug is crack cocaine, powder cocaine, or methamphetamine. I also limit the sample to only those with valid data on drug amount and sentence length, and exclude cases in non-U.S. districts (e.g. Puerto Rico, Guam, and the Virgin Islands). ${ }^{4}$

The initial analyses in this paper will use data covering the 2009 to 2012 fiscal years. This initial time period of 2009-2012 contains 11,479 defendants convicted for crack that are included in the analysis. However, data going back to 2002 will be used subsequently to analyze earlier policy changes to crack cocaine sentencing.

The Fair Sentencing Act (FSA) was made effective August 3, 2010. Therefore, for ease of reference throughout the paper, a year will be counted as going from August $1^{\text {st }}$ of the previous calendar year to July $31^{\text {st }}$. So, for example, when I refer to the year 2010, I am referring to the time period going from August $1^{\text {st }}$ of 2009 to July $31^{\text {st }}$ of 2010 . This is done so that all months in and prior to year 2010 are prior to the FSA being made effective, and all months in and after year 2011 are after the FSA was made effective.

Table 2 shows basic pre-FSA summary statistics by drug (i.e., for defendants convicted in the years 2009 and 2010). As can be seen, crack defendants on average received substantially longer sentences when compared to those convicted for powder cocaine. Table 2 also shows that while over 80 percent of crack defendants are black, less than 30 percent of defendants convicted for powder cocaine are black. Finally, as can be seen in the last row of Table 2, a much higher fraction of crack defendants had previous felony convictions than those defendants convicted for other drugs. Hence, as has been highlighted before, the sentencing of crack defendants is an issue that by and large is something that primarily impacts black Americans and repeat offenders.

\footnotetext{
${ }^{4}$ Including observations without valid drug amounts generally has no appreciable impact on the results.
} 


\section{Evaluating the Impact of the Fair Sentencing Act on Average Sentence Lengths for Crack Defendants}

Figure 1 shows a naïve assessment of the impact of the FSA by simply looking at how the mean sentence for crack defendants changed between the twenty four months prior to the FSA and the twenty four months following the implementation of the FSA. As can be seen, the mean sentence fell by 17 months, or about 16 percent.

However, as discussed above, this simple pre- to post- FSA difference in mean sentence length for crack defendants (with relatively large time blocks on either side of the passage of the FSA) may be a problematic assessment of the direct effect of the FSA on sentence lengths for crack defendants. The top line in Figure 2 shows the time trend in mean sentence length for crack defendants, from the years 2009 to 2012. As stated earlier, each year refers to time periods going from August 1st to July 31st (e.g., year 2010 here refers to August 12009 to July 31 2010), meaning the FSA effective date of August 3, 2010 means it became effective just after the year 2010 (vertical line on Figure 5). As can be seen quite clearly, the mean sentence for crack defendants was already falling well prior to the implementation of the FSA, and at least at this aggregated level, there does not appear to be any obvious change or jump in the trend following the implementation of the FSA.

As a point of comparison, Figure 2 also shows the trends in the sentencing for powder cocaine offenders which should not have been directly affected by the FSA. As can be seen, the mean sentence length for cocaine offenders fell a small amount following the implementation of the FSA. This at least suggests that there were no countervailing sentencing policy changes that were pushing up sentences for drug crimes as a whole during the time the FSA was implemented. Interestingly, the trend in mean cocaine sentences was actually quite flat prior to the implementation of the FSA, but started a downward trend right around the implementation of the FSA. Therefore, one thing this picture makes clear is that even though cocaine sentences should not have been impacted by the FSA, it would not be appropriate to do a difference-indifference estimate using the trends in cocaine sentencing as the "missing counterfactual" trend, since the parallel pre-treatment trends requirement for such a procedure is clearly not met (the same is true for methamphetamine cases).

Table 3 shows the results of several OLS regression analyses corresponding to equation (1) for crack cases from years 2009 to 2011. Specification (1) controls for only a linear monthly 
time trend and a post-FSA dummy. Specification (2) further controls for defendant characteristics including race, gender, drug quantity, and criminal history via dummy variables. Recognizing that the FSA is essentially being imposed on judicial districts (as it is the combination of the judges and prosecutors in a district that essentially apply their interpretation of federal sentencing policy), and districts may differ not only in their general sentencing severity but also in their variance in sentencing policy, specification (3) further controls for district fixed-effects and uses two-way clustered standard errors by district and time (monthly). ${ }^{5}$ As can be seen, in all of the specifications (1) - (3) the coefficient on the linear time-trend is always significantly negative, suggesting expected sentences have been falling by about 0.8 months per month, or a little over 9 months per year. However, the coefficient on the post-FSA indicator variable is never significantly different than zero (and indeed is positive in sign). Indeed, even if one looks at the 95 percent confidence intervals surrounding the point estimates on the post-FSA coefficients (in brackets below standard errors), there is very little evidence of a notable change in trend following the implementation of the FSA. For example, if we take the lower bound on the 95 percent confidence interval in specification (3) (what I would argue is the preferred specification), the strongest interpretation of the results suggest that the FSA could have pushed sentences for crack offenders down by a little under 4 months relative to the preFSA trend. Given the mean sentence for crack offenders pre-FSA was 109 months, even this would be a pretty small shift.

As a robustness check, rather than a regressing sentence length on a linear time trend and post-FSA indicator, specification (4) regresses sentence length on indicators for post-2009, post2010, and post-2011 (along with race and gender indicators, drug quantity, criminal history indicators, and district fixed-effects). If there is a notable acceleration in the time trend following the implementation of the FSA, then the coefficients on the post-2010 and/or post2011 indicators should be significantly more negative than the coefficient on the post-2009 indicator. As can be seen, the coefficients on all three of these indicators are quite similar (indeed a joint Chi-squared test cannot reject the hypothesis that they are all equal at any standard level of significance), all suggesting that expected sentences for crack offenders fall roughly 8-10 months per year between the year 2009 and the year 2012 (which is consistent with the coefficient on the time trend in specification (3)).

\footnotetext{
${ }^{5}$ Thanks to Colin Cameron for making his two-way clustered standard errors code available.
} 
As discussed previously, one might think that the FSA had a larger impact on crack defendants with previous criminal histories, as prior to the FSA a large fraction of mandatory minimum eligible first-time crack offenders were able to avoid the mandatory minimums due to their eligibility for the federal "safety-valve" relief (USSC 2011). Given this, specification (5) puts in separate time trends and post-FSA indicator variables for first-time offenders (criminal history category 1) and repeat offenders (criminal history category 2+). As can be seen, while again the coefficients on both of the time trend variables are negative and statistically significant, the coefficients on the two post-FSA dummies provide very little evidence that sentencing trends changed for either of these two groups following the implementation of the FSA.

Given distribution of sentence lengths is actually quite right skewed, simply using raw sentence length as the outcome variable in the regression specifications might not be the best fitting specification. So, Table 4 shows the results of specifications identical to those in Table 3 , but using natural $\log$ of sentence length as the outcome variable. As can again be seen, the results are essentially the same as in Table 3, again suggesting that sentencing trend for crack offenders did not change following the implementation of the FSA.

As discussed in Section III, another way to consider the direct impact of the changes to mandatory minimums dictated by the FSA is to examine whether sentences changed more in quantity categories directly impacted by the FSA relative to quantity categories not directly impacted by the FSA. To the extent to which raising the mandatory minimum quantity thresholds as dictated by the FSA was the primary driver of any changes in sentence lengths around the passage of the FSA, then we should see larger declines in sentence lengths among defendants convicted for crack quantities that were directly impacted by the FSA than defendants convicted for quantities not directly impacted by the FSA.

To look at this, Table 5 shows simple changes in mean sentence length for crack offenders in the time following the passage of the FSA relative to the time just prior to its passage across seven different quantity categories (to ensure ample number of cases in each cell, the pre-FSA period consists of the two years prior to the implementation of the FSA and the post-FSA consists of the two years following the implementation of the FSA). As alluded to above, the FSA itself only impacted defendants convicted for crack quantities between 0.005 kilograms to 0.028 kilograms (subject to a mandatory minimum before FSA but not after) and those convicted for crack quantities between 0.05 kilograms and 0.28 kilograms (subject to a 
lower mandatory minimum after the passage of the FSA than before). Any mandatory minimums associated with the other quantity categories were unaffected by the FSA. However, as also discussed above, the sentencing guidelines for all of the crack categories also changed just after the implementation of the FSA. Notably, though, by time the FSA was implemented in 2010 the guidelines were advisory rather than mandatory.

As can be seen in Table 5, mean sentences fell significantly for all crack defendants other than those convicted for quantities less than 0.005 kilograms. Most notably, both in raw terms and percentage terms, the fall in average sentence length for those in FSA affected quantity categories were roughly in line with the fall in average sentence lengths of those in quantity categories that were not directly affected by the FSA. Again, these findings suggest that much of the changes in sentencing of crack offenders around the passage of the FSA were not necessarily due to the changes in the mandatory minimums as dictated by the FSA.

Overall, the analyses in this section suggest that the FSA per se does not appear to be wholly responsible for the recent declines in the mean sentence for crack defendants, as sentences for crack offenders convicted for quantities that were ostensibly not directly affected by the FSA changes to the mandatory minimums saw similar declines as those that were, and maybe even more notably, there was a downward trend in sentencing for crack offenders starting well before the implementation of the FSA. This leaves a couple of questions. First, if not the FSA, what precipitated the downward trend in sentencing for crack offenders? Second, while the FSA may not have been the proximal cause of the downward trend in crack sentencing, what would have happened in its absence? In particular, to what extent would the downward trends in sentencing for crack offenders have been impeded were it not for the reforms to the crack mandatory minimums inherent in the FSA? The following sections consider these questions in more detail.

\section{So Why Have Crack Sentences Been Falling So Much?}

As discussed above, while the FSA is the only Congressional sentencing reform to occur for over 20 years, there have been a variety of other reforms to the United States sentencing guidelines starting in the mid-2000s. With the Booker decision in 2005, the Supreme Court held that the United States sentencing guidelines could no longer be deemed mandatory, but rather only advisory, with sentences being reviewed for "reasonableness." This still left considerable 
ambiguity regarding the role of the guidelines. The further decisions coming out of the Rita, Gall, and Kimbrough cases in 2007 clarified the role of the guidelines and indeed substantially weakened the role for the guidelines. In particular, the Kimbrough decision held that a judge could depart from the guidelines if he/she disagreed with the policy choices underlying the guideline sentence---most notably the disparate treatment of crack cocaine relative to powder cocaine. It is also important to note that the Booker, Rita, Gall, and Kimbrough decisions had no impact on the mandatory minimum sentencing statutes.

In addition to the Kimbrough decision in late 2007, the United States Sentencing Commission also altered the sentencing guidelines. Specifically, the US sentencing guidelines assign a sentencing range to a convicted offender based on a criminal history score and what is termed a "final offense level" which is a numeric score meant to capture the seriousness of the crime. Any quantity of a given drug corresponds to a particular offense level. In November 2007 the USSC amended the guidelines to reduce by two offense levels the base offense level assigned to each crack quantity threshold, a policy change sometimes referred to as the 2007 Crack Amendment. This effectively lowered the guideline sentence range associated with any crack cocaine conviction. As stated above, while these United States sentencing guidelines were no longer mandatory at the time of this change, they were still advisory.

To get a sense of the impact of these reforms to the US sentencing guidelines on sentencing, I use the Monitoring of Federal Criminal Sentences datasets spanning all the way back to 2002 to extend Figure 2 backward. Figure 3 shows this extended trend in mean sentence lengths for crack and powder cocaine from year 2002 to year 20012. There are four vertical lines shown in Figure 3. The dotted line simply shows the beginning date used in Figure 2 (August 2008 or 24 months prior to the implementation of the FSA). The solid lines show when significant changes to sentencing policy occurred over this time period. The vertical line furthest to the right indicates the implementation of the FSA. The vertical line all the way to the left indicates the Booker decision by the United States Supreme Court, and the middle solid vertical line indicates the Supreme Court decision regarding the Kimbrough case as well as the Crack Amendment to the United States sentencing guidelines. The vertical line for the FSA is placed between years 2010 and 2011 for the reasons discussed above (i.e., the year 2010 is defined to go from August 2009 to July 2010, with the FSA being implemented August 3, 2010). By contrast, the vertical line is placed mid-year 2005 for the Booker case, because it case was 
decided in January 2005, halfway between August 2004 and July 2005 (i.e., the year 2005), meaning some of the year 2005 cases were decided before Booker while others after. The vertical line for Kimbrough cases and the Crack Amendment is again placed between year 2007 and year 2008, as these events occurred during the fall of 2007, meaning they would primarily only apply to cases after year 2007 as defined here (i.e., August 2006 to July 2007).

As can be seen in Figure 3, the darker line shows that, other than a slight uptick in 2009, the mean sentence length for crack has been falling from 2007---the year of the Kimbrough decision and the Crack Amendment. By contrast, the lighter grey line shows that the mean sentence length for powder cocaine was roughly constant from 2005 until a slight downtick between 2010 and 2011 (the time when the FSA was implemented). One interpretation of this graph is that the changes to the force and structure of the USSC sentencing guidelines that occurred in late 2007 allowed judges and prosecutors to start acting on their desires to lessen sentence lengths for crack offenders.

To look at this more formally, analogous to the regression specification (4) in Table 3 , I regress sentence length on post-year indicators for each year and other defendant characteristics, or

$$
\text { (2) } S_{i}=\alpha+\sum_{j=2003}^{2012} \delta_{j} * \text { postYear }_{j}+\Phi X_{i}+\eta D+\varepsilon_{i}
$$

where again $S_{i}$, corresponds to the sentence given to a defendant $i$, and postYear ${ }_{j}$ is an dummy variable equal to one if the defendant was sentenced in Year $_{j}$ or after (for years 2003 - 2012). To again account for any changes in defendant characteristics over time, the vector $X_{i}$ includes race and gender dummies, criminal history dummies, and quantity category dummies, while $D$ is a vector of district fixed-effects to control for the possibility that more lenient districts may have received a larger or smaller fraction of crack cases over time. The final term, $\varepsilon_{i}$, is the residual error term. Like before, to test for a change in trend happening between year $j$ and $j-1$, we can examine whether the coefficient on the $\operatorname{post} \operatorname{Year}_{j}\left(\mathrm{i} . \mathrm{e} ., \delta_{\mathrm{j}}\right.$ ) is significantly different from the coefficient on post Year ${ }_{j-1}\left(\right.$ i.e., $\left.\delta_{j-1}\right)$. Intuitively, if mean sentences are constant over a given time period, then the $\delta_{\mathrm{j}}$ 's should equal zero over that time period. By contrast, if there is a constant downward trend over a given time period, meaning mean sentences are falling by $n$ months each year over that time period, then the $\delta_{\mathrm{j}}$ 's should roughly equal $-n$ over that time period. If there is a change in trend between year $j$ and $j-1$, we should see a change in $\delta_{\mathrm{j}}$ relative to $\delta_{\mathrm{j}-1}$. 
Table 6a shows the results from estimating equation (2) over a few different specifications for crack offenders. Specification (1) just regresses sentence length on all of the postYear $r_{j}$ indicators, specification (2) further controls for defendant race, gender, and criminal history (i.e., $\mathrm{X}_{\mathrm{i}}$ in equation (2)), and specification (3) further controls for district fixed effects (i.e., D in equation (2)). Specification (3) also uses two-way clustered standard errors by district

and time (monthly). The stars indicate the level of significance with respect to chi-squared test of the null hypothesis that the coefficient on the postYear ${ }_{j}$ indicator equals the coefficient on the post Year $_{j-1}$ indicator.

As can be seen in Table 6a, the coefficient on the postYear2008 indicator is negative and large in magnitude across all specifications, and a chi-squared test rejects the equality of the coefficients on the postYear2008 and postYear2007 indicators. This suggests that there was a substantial downward trend break happening in the time between year 2007 and year 2008, or right after the Kimbrough decision and the 2007 Crack Amendment to the USSC sentencing guidelines. While the chi-squared tests also indicate there may be trend breaks between the years 2004 and 2005, between the years 2008 and 2009, and between the years 2009 and 2010, there is again no indication of a trend break between the year 2011 and the year 2010 (i.e., when the FSA was implemented). This is obviously consistent with the graphical evidence from Figure 3 showing a big decline in mean sentence length for crack offenders between year 2007 and year 2008, followed by a slight uptick between year 2008 and year 2009, followed by a steady downturn from year 2009 and onward.

As a comparison, Table $6 \mathrm{~b}$ shows regressions analogous to those in Table $6 \mathrm{a}$, but using only the sample of powder cocaine defendants. As can be seen, there is little evidence of anything but a flat trend in sentencing of powder cocaine offenders throughout the whole time period from 2002-2012.

Overall, the results shown in Tables $6 \mathrm{a}$ and $6 \mathrm{~b}$ are consistent with the notion that the Kimbrough decision and the 2007 Crack Amendment to the USSC sentencing guidelines precipitated the beginning of a downward trend in mean sentence lengths for crack offenders, but not powder cocaine offenders, that was unaltered by the implementation of the FSA.

\section{What Would Have Happened to Crack Sentences in the Absence of the FSA?}


The results above show that the trend toward more leniency for crack offenders started well before the implementation of the FSA, and moreover, that the FSA did not appear to accelerate this trend. However, this does not mean that the FSA had no impact on sentencing. Indeed, in the absence of the FSA, the mandatory minimums may have impeded the downward trend in sentencing for crack offenders from continuing. This section attempts look at this issue in more detail.

In thinking about what sentences for crack offenders would have been in the absence of the FSA we first have to consider whether the FSA impacted other aspects of the judicial process beyond just sentencing. Maybe most notably, did the changes inherent in the FSA cause defendants to alter how much crack they carried and/or prosecutor's willingness and ability to bargain over the conviction quantity? The dataset used here does not provide information on the initial quantity any given defendant was charged with, so these issues cannot be looked at directly. We can however look at how the distribution of conviction quantities for crack defendants changed before and after the FSA was implemented.

Figure 4 looks at this issue in detail. This figure shows side-by-side histograms of the quantity distributions for each year from 2009 - 2012 (where the FSA was only in affect for the years 2011 and 2012). The two boxes in Figure 5 indicate the quantity bins that would have been directly impacted by the FSA. Again, defendants convicted for quantities in these two bins would be subject to a shorter mandatory minimum post-FSA than pre-FSA, while defendants in all other bins would be subject to the same mandatory minimum pre- and post- FSA. Curiously, both in the years before and the years after the FSA, the two FSA impacted quantity ranges contain more than half of the cases (this will be something to return to later). Moreover, the fraction of cases in each of these two bins changes somewhat before and after the FSA was implemented. Notably however, these changes go in different directions across these two quantity bins. The fraction of crack defendants convicted for quantities between 0.005 kilograms and 0.028 kilograms falls in the two years following the implementation of the FSA, while the fraction convicted for quantities between 0.05 kilograms and 0.28 kilograms rises somewhat in the two years following the implementation of the FSA. ${ }^{6}$

\footnotetext{
${ }^{6}$ Note, the dates we use here are the dates at which the defendants were sentenced. Clearly, however, a plea bargain stipulating the conviction quantity could have been struck well before the FSA was implemented even if the actual sentence was given post-FSA. This means that if there were substantial changes quantity manipulation following the implementation of the FSA, the above issue means that such changes may be somewhat obscured
} 
These findings are a little ambiguous regarding whether defendants or prosecutors significantly changed their behaviors in response to the FSA. While the distribution of conviction quantities does seem to change slightly in the quantities that would ostensibly be affected by the FSA, it does not do so in a uniform manner. From a defendant's perspective, the consequences from being convicted for a quantity between 0.005 kilograms and 0.028 kilograms, or for a quantity between 0.05 kilograms and 0.28 kilograms, should be lower post-FSA. Similarly, postFSA, judges and prosecutors should ostensibly have more discretion over the sentences given to defendants convicted for quantities between 0.005 kilograms and 0.028 kilograms, and between 0.05 kilograms and 0.28 kilograms, than they did before. Both of these forces would seem to suggest that we would see a significantly higher fraction of defendants in these two categories post-FSA than pre-FSA, but as stated above, we find that is only true in one of these categories, with exactly the opposite occurring in the other. In general, Figure 4 does not suggest large changes in criminal or prosecutor behavior with respect to real or charged crack quantities.

Another aspect of behavior that may have changed in response to the FSA is the willingness of prosecutors to invoke the federal "safety-valve" provision. As alluded to in Section II, defendants ostensibly eligible for a federal mandatory minimum can be given a sentence less than the mandatory minimum if they are deemed eligible for the federal "safetyvalve" program, which can occur if the prosecutor determines that the defendant has a minimal criminal history, there was no gun or violence used I the commission of the crime, the defendant was not a leader or organizer, and the defendant was determined to be cooperative. While some of these criteria are quite objective (e.g., minimal criminal history), most leave substantial discretion up to the prosecutor (e.g., the defendant was cooperative, the defendant was not an organizer or leader). Hence, one might wonder whether prosecutors became less likely to grant safety-valve eligibly after the FSA raised the quantity thresholds determining eligibility for the mandatory minimums for crack.

Figure 5 shows that the rate at which the safety-valve was invoked for crack defendants was essentially unchanged surrounding the implementation of the FSA, hovering right around 12 percent. To look at this issue somewhat more rigorously, Table 7 shows the results of OLS linear probability models, where a binary variable equaling one if the safety-valve was reported to be

when comparing the year 2010 to the year 2011. Therefore, it might be cleaner to focus mostly on the year 2012 results relative to the pre-FSA years of 2009 and 2010. 
invoked (and zero otherwise) was regressed on a post-FSA indicator variable, a monthly time trend, and other defendant characteristics. The results in specification (1) mirror the result shown in Figure 6, showing that without conditioning on anything else, there is no significant time trend or change in the likelihood of the safety-valve being invoked post-FSA. Specification (2) further controls for race, gender, criminal history, and quantity, while specification (3) further adds district fixed-effects (and uses two-way clustered standard errors on district and monthly time). As can be seen by the extremely small in magnitude coefficients on the post-FSA indicator (along with relatively tight confidence intervals), even controlling for defendant characteristics, there is no evidence that use of the safety-valve changed following the implementation of the FSA. $^{7}$

Given the results above, let us consider again the extent to which the FSA prevented mandatory minimums from impeding the pre-FSA downward trends in sentencing for crack offenders from continuing. While determining a precise answer to this question may not be possible, we can potentially determine a reasonable bound. Specifically, let us suppose that preFSA, the mandatory minimums were already generally binding for defendants convicted for quantities between 0.005 and 0.028 kilograms and for defendants convicted for quantities between 0.05 and 0.28 kilograms (the two quantity categories directly impacted by the FSA). In other words, pre-FSA, prosecutors and judges generally wanted to give sentences to such defendants at or less than required by the mandatory minimum legislation but couldn't. Given this, in the absence of the FSA, even if prosecutors and judges wanted to continue the trend of becoming more lenient with respect to sentencing crack defendants, they would have been constrained to give sentences to defendants in these quantity categories similar to what they were giving to like defendants pre-FSA. Therefore, we can compute "counterfactual" sentences for defendants convicted post-FSA for quantities in the $0.005-0.028$ kilogram range and the 0.05 0.28 kilogram range by estimating what they would have received given their characteristics had they been convicted just prior to the implementation of the FSA. Given the FSA did not affect the mandatory minimums relevant to those convicted for quantities of crack outside of the two above quantity categories, the "counterfactual" sentences for defendants convicted for such quantities post-FSA simply equal to their actual sentences.

\footnotetext{
${ }^{7}$ I used a linear probability OLS model for simplicity given the number of fixed-effects and clustered standard errors. However, little changes if I use a probit model.
} 
To estimate these counterfactual sentences for crack defendants convicted for quantities in the $0.005-0.028$ kilogram range and the $0.05-0.28$ kilogram range post-FSA, I first regress sentence length on quantity guidelines category dummies, criminal history category dummies, district dummies, and indicators for race and gender, using just the sample of crack defendants convicted for quantities in the $0.005-0.028$ kilogram range in the 12 months prior to the implementation of the FSA. I then used the coefficients from this regression to predict "counterfactual" sentences for each post-FSA crack defendant convicted for a quantity in the 0.005 - 0.028 kilogram range based on their characteristics. I then do an analogous procedure for each post-FSA defendant convicted for a quantity in the $0.05-0.28$ kilogram range. In other words, somewhat analogous to a Oaxaca-Blinder decomposition, I estimate "counterfactual" sentences for defendants convicted for quantities affected by the FSA by using their characteristics along with regression coefficients calculated with a pre-FSA sample to map the characteristics of the post-FSA sample into counterfactual expected sentences. As stated above though, for post-FSA crack defendants whose conviction quantities were not affected by the FSA, their "counterfactual" sentence is the same as their actual sentence.

Figure 6 shows the results from this "counterfactual" exercise. The darker grey line (with diamonds) shows the actual trend in mean sentence lengths for crack offenders from the year 2009 to year 2012 as shown previously in Figure 2. The lighter grey line (with squares) shows the trend in mean sentence lengths for crack offenders from $2009-2012$ under the "counterfactual" sentences as described above. As can be seen, this counterfactual suggests mean sentences for crack offenders would have stagnated at pre-FSA levels, meaning that in the absence of the FSA the overall mean sentence for crack offenders would be almost 8 percent higher in year 2011 (104 months versus 97 months in actuality) and almost 20 percent longer in year 2012 (105 months versus 88 months).

The magnitude of the difference between what actually happened and this counterfactual arguably may seem somewhat implausible given much of the discussion above, particularly given these counterfactual sentences equal the actual sentences for all of those convicted for crack quantities outside of the 0.005 - 0.028 kilogram and $0.05-0.28$ kilogram range post-FSA. However, recall from Figure 5 that almost 65 percent of crack defendants are convicted for quantities within one of these two quantity categories (both before and after the FSA). Moreover, the above results likely overstate how much the downward trend in sentencing for 
crack offenders would have been impeded by mandatory minimums in the absence of the FSA, as it assumes that the mandatory minimums were already binding with respect to the sentencing of crack defendants in the affected quantity categories pre-FSA. This is likely a strong assumption. Regardless, these results are at least suggestive that even though the FSA didn't accelerate the downward trend in sentencing of crack offenders, without the FSA, this downward trend would have notably decelerated.

\section{The FSA and the Crack/Powder Cocaine Sentencing Gap}

As alluded to previously, another of the main motivations for the FSA was to reduce the sentencing disparity between crack defendants and powder cocaine defendants, particularly for those convicted for similar amounts. This section examines this issue more directly.

The dark grey line with diamonds in Figure 7 shows the evolution of the crack/powder cocaine gap for sample to defendants convicted for quantities under 3 kilograms (which constitutes over 95 percent of crack cases). ${ }^{8}$ Once again, vertical lines are put into to show the Booker decision, the Kimbrough decision and the 2007 Crack Amendment to the sentencing guidelines, and the FSA. As can be seen, the crack/powder cocaine sentencing gap experienced a precipitous decline following the Kimbrough decision and the 2007 Crack Amendment to the sentencing guidelines, with the ratio of mean crack sentences to mean powder cocaine sentences falling from around 2.5-to-1 to about 2-to-1. However, this ratio has stayed relatively constant every year since, including following the implementation of the FSA.

The above result is not surprising given the results from Figure 2 showing that the mean sentences for both crack and powder cocaine had been declining over the 2009 - 2012 period, and that this downward trend in sentencing for crack defendants showed no evidence of accelerating following the implementation of the FSA. However, it again might be useful to consider a "counterfactual" of what would have happened in the absence of the FSA. As discussed above, while the FSA may not have accelerated the downward trend in sentencing for crack offenders, this downward trend may have been stymied in its absence.

\footnotetext{
${ }^{8}$ The reason I truncated quantity at 3 kilograms in for the analysis shown in Figure $\mathrm{X}$ is because I am most interested in how the crack cocaine/powder cocaine sentencing gap for defendants convicted for roughly similar amounts. While over 95 percent of crack defendants were convicted for quantities under 3 kilograms, only about one-third of powder cocaine defendants were convicted for quantities under 3 kilograms. So without truncating, we would be comparing crack defendants to cocaine defendants who were on average convicted for much greater quantities.
} 
Looking again at Figure 7, the light grey line with squares shows the "counterfactual" estimate of what would have happened to this ratio in the absence of the FSA. Again, this counterfactual assumes that prior to the FSA, prosecutors/judges were constrained by the mandatory minimums in 2010, so that in the absence of the FSA, those for whom the FSA lessened the relevant mandatory minimum sentence (i.e., those convicted for quantities between $0.005-0.028$ kilograms and $0.05-0.28$ kilograms post-FSA) would have received a sentence consistent with the year 2010 practices in the absence of the FSA. As can be seen, to the extent to which sentencing practices for defendants convicted for crack quantities between 0.005 0.028 kilograms and $0.05-0.28$ kilograms post-FSA would have been constrained to pre-FSA levels if the mandatory minimums for crack had not been adjusted by the FSA, the ratio of crack to powder cocaine mean sentences may have risen again up to 2.3-to-1 rather than its current level of 2-to-1. In other words, by 2012, the crack/powder cocaine sentencing gap may have been about 15 percent higher in the absence of the FSA.

\section{Conclusion}

In contrast to some of the lofty rhetoric, the findings of this study suggest that the changes to the mandatory minimum sentence quantity thresholds for crack offenders as dictated by the Fair Sentencing Act of 2010 (FSA) were actually quite modest in their impact. The FSA does not appear to be the primary force responsible for the fall in average crack cocaine sentences following the passage of the FSA, nor does it appear that the FSA in and of itself substantially decreased the sentencing disparity between crack cocaine defendants and powder cocaine defendants. Rather, it appears that changes the both the structure and implementation of the United States sentencing guidelines in the mid-2000s allowed prosecutors and/or judges to act on their preferences for more leniency with respect to sentencing drug defendants, particularly crack defendants. While the FSA itself does not appear to have substantially accelerated these trends toward greater leniency, the evidence presented in this paper suggests that it helped prevent the mandatory minimums from impeding the continuation of these trends. Going forward, it is quite clear that to further reduce the crack/powder cocaine sentencing gap, the US Congress must work with the US Sentencing Commission to alter both the eligibility standards for mandatory minimums as well as the sentencing guidelines for crack. 


\section{References}

Beaver, Alyssa L. (2010). "Getting a Fix on Cocaine Sentencing Policy: Reforming the Sentencing Scheme of the Anti-Drug Abuse Act of 1986." Fordham Law Review 78: 2531-2575.

Bjerk, David. (2005). "Making the Crime Fit the Penalty: The Role of Prosecutorial Discretion Under Mandatory Minimum Sentencing." Journal of Law and Economics 48(2): 591-627.

Caulkins, Jonathan P., C. Peter Rydell, William L. Schwabe, and James Chiesa. (1997). Mandatory Minimum Drug Sentences: Throwing Away the Key or the Taxpayers' Money? RAND Monograph, Santa Monica, CA.

Chitwood, Dale, James Rivers, and James Inciardi. (1996). The American Pipe Dream: Crack Cocaine and the Inner City. Austin: Harcourt Brace College Publishers.

Fischman, Joshua B., and Max M. Schanzenbach. (2012). "Racial Disparities Under the Federal Sentencing Guidelines: The Role of Judicial Discretion and Mandatory Minimums." Journal of Empirical Legal Studies 9(4): 729-764.

Fryer, Roland, Paul S. Heaton, Steven D. Levitt, and Kevin M. Murphy. (2013). Measuring Crack Cocaine and Its Impact. Economic Inquiry 51(3): 1651-1681.

Grogger, Jeffrey and Michael Willis. (2000). "The Emergence of Crack Cocaine and the Rise in Urban Crime Rates.” Review of Economics and Statistics 82(4): 519-529

Hartley, Richard, Sean Maddan, and Cassia Spohn. (2007). "Prosecutorial Discretion: An Examination of Substantial Assistance Departures in Federal Crack-Cocaine and Powder Cocaine Cases.” Justice Quarterly 24(3): 382-407.

Helland, Eric and Alex Tabarrok. 2007. "Does Three Strikes Deter? A Non-parametric Estimation.” Journal of Human Resources 42(2): 309-330. 
Kautt, Paula and Cassia Spohn. 2002. "Crack-ing Down on Black Drug Offenders? Testing for Interactions Among Offenders' Race, Drug Type, and Sentencing Strategy in Federal Drug Sentences." Justice Quarterly 19(1): 1-35.

Kerr, Peter. (1986). "Anatomy of the Drug Issue: How, After Years, It Erupted." New York Times, Nov. 17, 1986.

Klein, Malcolm W, Cheryl L. Maxon, Lea C. Cunningham. (1991). "'Crack', Street Gangs, and Violence." Criminology 29(4).

Kurlychek, Megan C., Jeffery T. Ulmer, and John H. Kramer. (2007). "Prosecutorial Discretion and the Imposition of Mandatory Minimum Sentences" Journal of Research in Crime and Delinquency 44(4): 427-458:

LaCasse, Chantale and A. Abigail Payne. (1999). "Federal Sentencing Guidelines and Mandatory Minimum Sentences: Do Defendants Bargain in the Shadow of the Judge?" Journal of Law and Economics 42(S1): 245-270.

Loftin, Colin, Milton Heumann and David McDowall (1983). "Mandatory Sentencing and Firearms Violence: Evaluating an Alternative to Gun Control." Law and Society Review 17(2): 287-318.

Loftin, Colin, David McDowall and Brian Wiersema (1992). "A Comparative Study of the Preventive Effects of Mandatory Sentencing Laws for Gun Crimes." Journal of Criminal Law and Criminology 83(2): 378-394.

Marvell, Thomas B. and Carlisle E. Moody. (2001). "The Lethal Effects of Three-Strikes Laws." Journal of Legal Studies 30(1): 89-106.

Reinarman, Craig; Waldorf, Dan; Murphy, Sheigla B.; Levine, Harry G. (1997). "The Contingent Call of the Pipe: Bingeing and Addiction Among Heavy Cocaine Smokers". In Reinarman, 
Craig; Levine, Harry G. Crack in America: Demon Drugs and Social Justice. Berkeley, California: University of California Press.

Shepherd, Joanna M. (2002). Fear of the First Strike: The Full Deterrent Effect of California's Two- and Three-Strikes Legislation, Journal of Legal Studies 31(1): 159 - 201.

Starr, Sonja and M. Marit Rehavi. (2013). "Mandatory Sentencing and Racial Disparity: Assessing the Role of Prosecutors and the Effects of Booker." Yale Law Journal 123(2): 2-80.

Tonry, Michael. (1992). "Mandatory Penalties.” Crime and Justice 16: 243-273.

Vagins, Deborah J and. Jesselyn McCurdy. (2006). Cracks in the System: Twenty Years of the Unjust Federal Crack Cocaine Law, American Civil Liberties Union Monograph: New York, NY.

U.S.S.C. (2002). "Cocaine and Federal Sentencing Policy." United States Sentencing Commission Special Report to Congress, May 2002.

U.S.S.C. (2011). "Mandatory Minimum Penalties in the Federal Criminal Justice System." United States Sentencing Commission Report to the Congress, October 2011. 
Table 1a: Federal Mandatory Minimum Drug Sentences, by drug and quantity, Pre-FSA

\begin{tabular}{cccc}
\hline & 1st Drug Offense & $\begin{array}{c}\text { 2nd Drug } \\
\text { Offense }\end{array}$ & $\begin{array}{c}\text { 3rd Drug } \\
\text { Offense }\end{array}$ \\
\hline $\begin{array}{c}\text { Marijuana } \\
100 \mathrm{~kg} \text { or more }\end{array}$ & $5 \mathrm{yrs}$ & $10 \mathrm{yrs}$ & $\begin{array}{c}10 \mathrm{yrs} \\
\text { Life }\end{array}$ \\
$\begin{array}{l}\text { 1000 kg or more } \\
\text { Methamphetamine }\end{array}$ & $10 \mathrm{yrs}$ & $20 \mathrm{yrs}$ & \\
$0.05 \mathrm{~kg}$ or more & $5 \mathrm{yrs}$ & $10 \mathrm{yrs}$ & $10 \mathrm{yrs}$ \\
$0.5 \mathrm{~kg}$ or more & $10 \mathrm{yrs}$ & $20 \mathrm{yrs}$ & Life \\
$\begin{array}{c}\text { Heroin } \\
0.1 \mathrm{~kg} \text { or more }\end{array}$ & $5 \mathrm{yrs}$ & $10 \mathrm{yrs}$ & $10 \mathrm{yrs}$ \\
$1 \mathrm{~kg}$ or more & $10 \mathrm{yrs}$ & $20 \mathrm{yrs}$ & Life \\
$\begin{array}{l}\text { Powder Cocaine } \\
0.5 \mathrm{~kg} \text { or more }\end{array}$ & $5 \mathrm{yrs}$ & & $10 \mathrm{yrs}$ \\
$5 \mathrm{~kg}$ or more & $10 \mathrm{yrs}$ & $20 \mathrm{yrs}$ & Life \\
& & & \\
Crack Cocaine & & $10 \mathrm{yrs}$ & $10 \mathrm{yrs}$ \\
$0.005 \mathrm{~kg}$ or more & $5 \mathrm{yrs}$ & $20 \mathrm{yrs}$ & Life \\
$0.05 \mathrm{~kg}$ or more & $10 \mathrm{yrs}$ & &
\end{tabular}

Table 1b: Changes in Mandatory Minimum Cutoff Quantities

for Crack Cocaine, Pre- and Post- FSA

1st Drug Offense 2nd Drug Offense 3rd Drug Offense

Pre-FSA

$0.005 \mathrm{~kg}$ or more

5 yrs

10 yrs

10 yrs

$0.05 \mathrm{~kg}$ or more

10 yrs

20 yrs

Life

Post-FSA

$0.028 \mathrm{~kg}$ or more

5 yrs

$10 \mathrm{yrs}$

10 yrs

$0.28 \mathrm{~kg}$ or more

10 yrs

20 yrs

Life 
Table 2: Summary Characteristics by Drug Type (Pre-FSA)

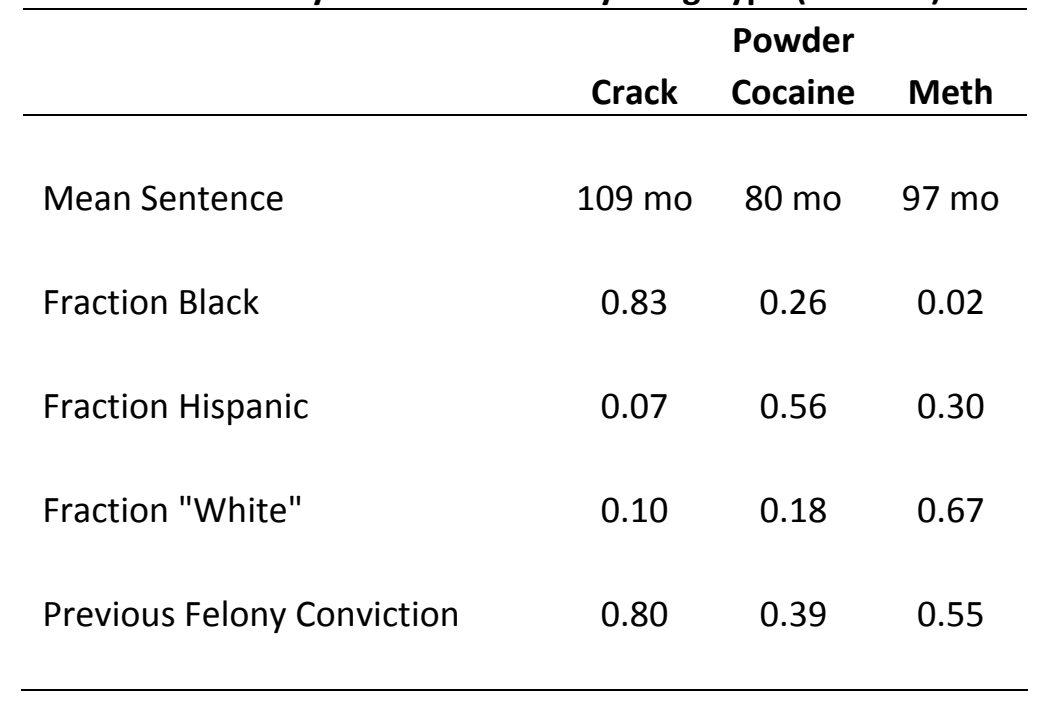


Figure 1: Mean sentences for crack defendants pre-vs. post-FSA

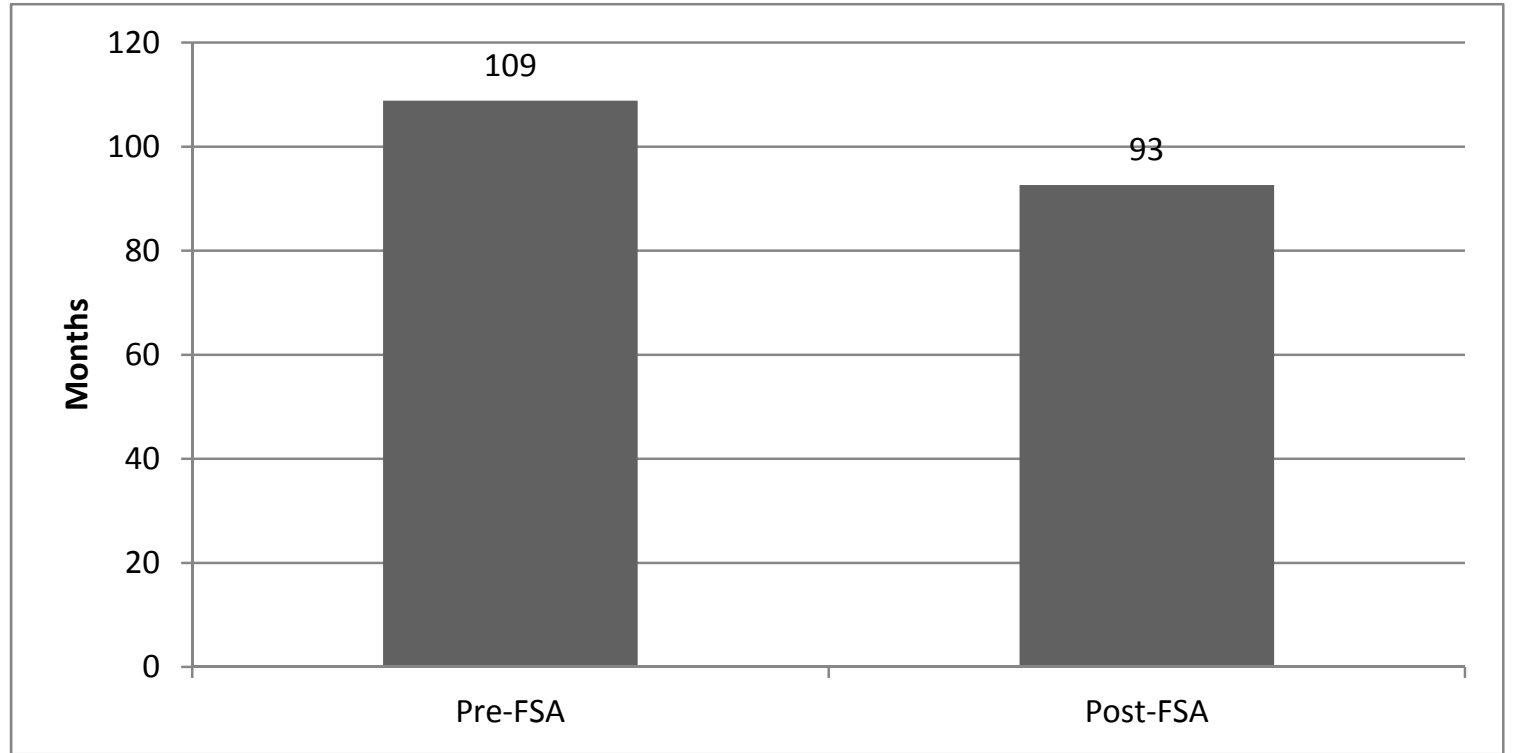

Notes: "Pre-FSA" time periods spans August 12008 - July 31 2010. "Post-FSA" time period spans August 12010 - July 312012.

Figure 2: Mean sentence length by drug (August 2008 - August 2012)

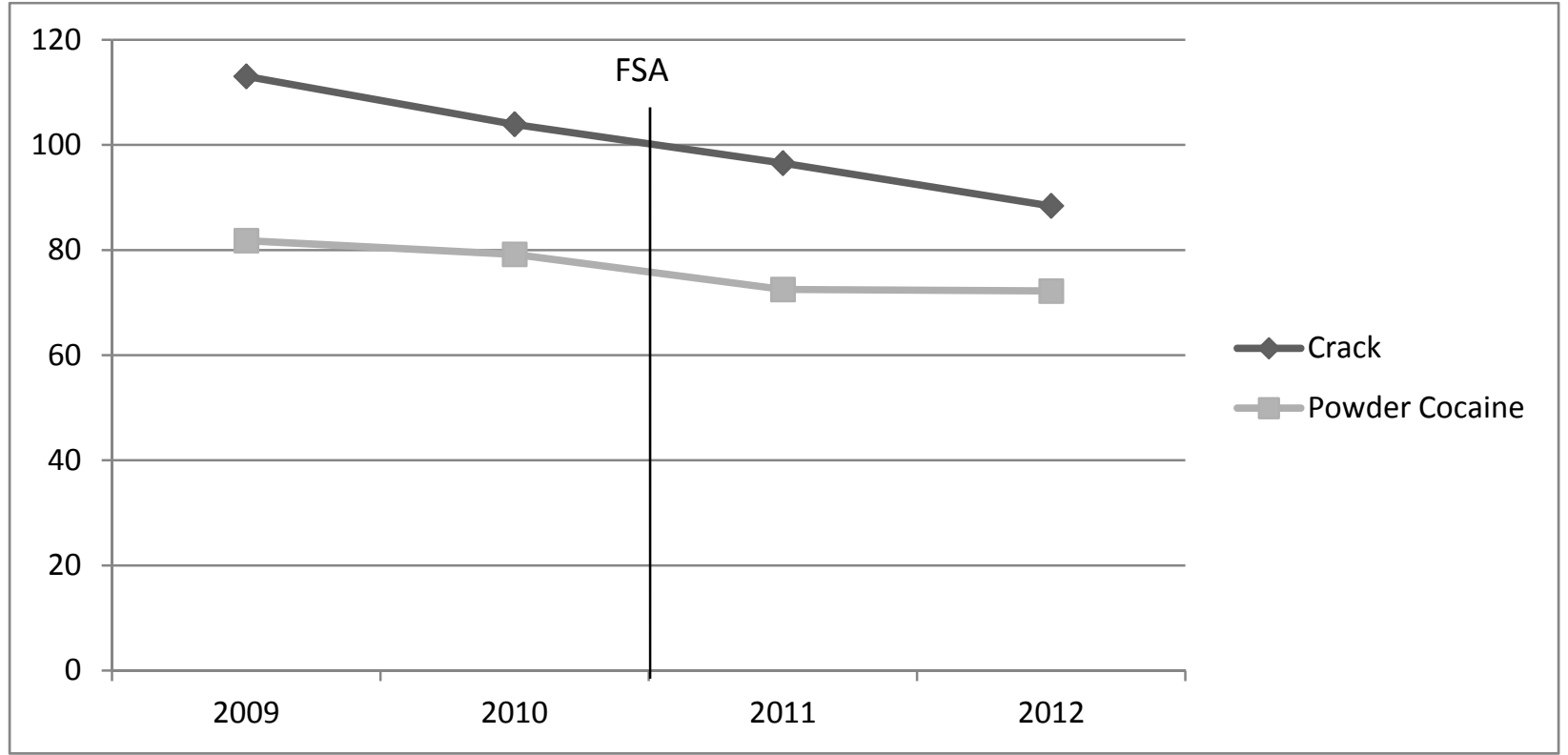

Notes: The FSA was made effective date August 3, 2010. So for ease of reference, each "year" is counted as running from August to July (e.g., "2010" runs from August 2009 to July 2010), meaning all of "year 2010" was before FSA took effect. 
Table 3: OLS Analysis for Trend Break Following Fair Sentencing Act of 2010 (Dependent Variable - Sentencing Length in Months)

\begin{tabular}{|c|c|c|c|c|c|}
\hline & \multicolumn{5}{|c|}{ Specification } \\
\hline & $(1)$ & (2) & (3) & (4) & (5) \\
\hline \multirow[t]{2}{*}{ time trend (monthly) } & $-0.77 * * *$ & $-0.83 * * *$ & $-0.80 * * *$ & & \\
\hline & $(.123)$ & $(.093)$ & $(.112)$ & & \\
\hline Coefficient on Post-FSA & 2.56 & 1.51 & 1.54 & & \\
\hline \multirow[t]{2}{*}{ indicator } & $(3.367)$ & $(2.559)$ & $(2.740)$ & & \\
\hline & {$[-4.0,9.2]$} & {$[-3.5,6.5]$} & {$[-3.8,6.9]$} & & \\
\hline \multirow[t]{2}{*}{ Post-year 2009 indicator } & & & & $-9.82 * * *$ & \\
\hline & & & & $(2.350)$ & \\
\hline \multirow[t]{2}{*}{ Post-year 2010 indicator } & & & & $-7.39 * * *$ & \\
\hline & & & & $(2.220)$ & \\
\hline \multirow[t]{2}{*}{ Post-year 2011 indicator } & & & & $-10.67 * * *$ & \\
\hline & & & & $(2.024)$ & \\
\hline \multirow{3}{*}{$\begin{array}{l}\text { Coefficient on Post-FSA } \\
\text { indicator (Crim hist cat }=1 \text { only) }\end{array}$} & & & & & 1.32 \\
\hline & & & & & $(3.706)$ \\
\hline & & & & & {$[-5.9,8.6]$} \\
\hline \multirow[t]{2}{*}{ time trend (Crim hist cat $=1$ only) } & & & & & $-0.53 * * *$ \\
\hline & & & & & $(.162)$ \\
\hline \multirow{3}{*}{$\begin{array}{l}\text { Coefficient on Post-FSA } \\
\text { indicator (Crim hist cat } \geq 2 \text { only) }\end{array}$} & & & & & 1.63 \\
\hline & & & & & $(3.073)$ \\
\hline & & & & & {$[-4.4,7.6]$} \\
\hline \multirow[t]{2}{*}{ time trend (Crim hist cat $\geq 2$ only) } & & & & & $-0.86 * * *$ \\
\hline & & & & & $(.118)$ \\
\hline race and gender indicators & no & yes & yes & yes & yes \\
\hline crim. history category indicators & no & yes & yes & yes & yes \\
\hline quantity & no & yes & yes & yes & yes \\
\hline (by guideline cell) & & & & & \\
\hline $\begin{array}{l}\text { two-way clustered standard } \\
\text { errors by district and month }\end{array}$ & no & no & yes & yes & yes \\
\hline
\end{tabular}


Notes: Crack cases only. Data runs from August 1, 2008 to July 31, 2012. Standard errors in parentheses, brackets show $95 \%$ confidence interval. $* * *$ indicates significance at $1 \%$ level. 
Table 4: OLS Analysis for Trend Break Following Fair Sentencing Act of 2010 (Dependent Variable - Natural Log of Sentencing Length)

\begin{tabular}{|c|c|c|c|c|c|}
\hline & \multicolumn{5}{|c|}{ Specification } \\
\hline & (1) & (2) & (3) & (4) & (5) \\
\hline \multirow[t]{2}{*}{ time trend (monthly) } & $-0.01 * * *$ & $-0.01 * * *$ & $-0.01 * * *$ & & \\
\hline & $(.002)$ & $(.001)$ & $(.002)$ & & \\
\hline Coefficient on Post-FSA & 0.02 & 0.00 & 0.01 & & \\
\hline \multirow[t]{2}{*}{ indicator } & $(.046)$ & $(.035)$ & $(.048)$ & & \\
\hline & {$[-0.07,0.11]$} & {$[-0.07,0.07]$} & {$[-0.08,0.11]$} & & \\
\hline \multirow[t]{2}{*}{ Post-year 2009 indicator } & & & & $-0.17 * * *$ & \\
\hline & & & & $(.034)$ & \\
\hline \multirow[t]{2}{*}{ Post-year 2010 indicator } & & & & $-0.12 * * *$ & \\
\hline & & & & $(.035)$ & \\
\hline \multirow[t]{2}{*}{ Post-year 2011 indicator } & & & & $-0.12 * * *$ & \\
\hline & & & & $(.031)$ & \\
\hline $\begin{array}{l}\text { Coefficient on Post-FSA } \\
\text { indicator (Crim hist cat }=1\end{array}$ & & & & & 0.07 \\
\hline \multirow[t]{2}{*}{ only) } & & & & & $(.126)$ \\
\hline & & & & & {$[-0.18,0.31]$} \\
\hline \multirow[t]{2}{*}{ time trend (Crim hist cat $=1$ only) } & & & & & $-0.02 * * *$ \\
\hline & & & & & $(.005)$ \\
\hline Coefficient on Post-FSA & & & & & 0.00 \\
\hline \multirow[t]{2}{*}{ indicator (Crim hist cat $\geq 2$ only) } & & & & & $(.035)$ \\
\hline & & & & & {$[-0.07,0.07]$} \\
\hline \multirow[t]{2}{*}{ time trend (Crim hist cat $\geq 2$ only) } & & & & & $-0.01 * * *$ \\
\hline & & & & & $(.001)$ \\
\hline race and gender indicators & no & yes & yes & yes & yes \\
\hline crim. history category indicators & no & yes & yes & yes & yes \\
\hline quantity & no & yes & yes & yes & yes \\
\hline (by guideline cell) & & & & & \\
\hline two-way clustered standard & no & no & yes & yes & yes \\
\hline
\end{tabular}


errors by district and month

Notes: Crack cases only. Data runs from August 1, 2008 to July 31, 2012. Dependent variable equals zero if no prison sentence. Standard errors in parentheses, brackets show 95\% confidence interval. 
Table 5: Pre- vs Post-FSA Changes in Mean Sentence Length, by Quantity Crack Cases Only (2009 - 2012)

\begin{tabular}{|c|c|c|c|c|c|}
\hline \multirow[b]{2}{*}{ Quantity (kg) } & \multirow{2}{*}{$\begin{array}{c}\text { Affected } \\
\text { by FSA? }\end{array}$} & \multicolumn{2}{|c|}{$\begin{array}{l}\text { Mean Sentence } \\
\text { (months) }\end{array}$} & \multirow{2}{*}{$\begin{array}{c}\text { Raw } \\
\text { Difference }\end{array}$} & \multirow{2}{*}{$\begin{array}{c}\text { Percent } \\
\text { Difference }\end{array}$} \\
\hline & & Pre-FSA & Post-FSA & & \\
\hline \multirow[t]{2}{*}{$<0.005$} & no & 54.98 & 50.62 & -4.36 & $-7.9 \%$ \\
\hline & & $(2.558)$ & (3.163) & $(4.068)$ & (7.173) \\
\hline \multirow[t]{2}{*}{$0.005-0.028$} & yes & 81.57 & 67.78 & $-13.78 * * *$ & $-17 \% * * *$ \\
\hline & & $(1.478)$ & (1.991) & $(2.480)$ & $(2.868)$ \\
\hline \multirow[t]{2}{*}{$0.028-0.05$} & no & 94.49 & 79.98 & $-14.51 * * *$ & $-15 \% * * *$ \\
\hline & & $(2.986)$ & $(2.780)$ & $(4.080)$ & (3.976) \\
\hline \multirow[t]{2}{*}{$0.05-0.28$} & yes & 120.69 & 97.93 & $-22.76 * * *$ & $-19 \% * * *$ \\
\hline & & $(1.782)$ & (1.775) & $(2.515)$ & $(1.896)$ \\
\hline \multirow[t]{2}{*}{$0.28-1$} & no & 144.81 & 126.84 & $-17.97 * * *$ & $-12 \% * * *$ \\
\hline & & $(4.488)$ & (4.171) & $(6.127)$ & $(3.958)$ \\
\hline \multirow[t]{2}{*}{$1-3$} & no & 176.00 & 140.49 & $-35.50 * * *$ & $-20 \% * * *$ \\
\hline & & (6.913) & $(6.538)$ & $(9.515)$ & $(4.861)$ \\
\hline \multirow[t]{2}{*}{$>3$} & no & 209.14 & 168.75 & $-40.39 * * *$ & $-19 \% * * *$ \\
\hline & & $(7.838)$ & (7.171) & $(10.623)$ & $(4.572)$ \\
\hline
\end{tabular}

Notes: "Pre-FSA" spans August 1, 2008 - July 31, 2010. "Post-FSA" spans August 1, 2010 - July $31,2012 . * * *$ indicates significance at $1 \%$ level. 
Figure 3: Mean sentence length by drug (Aug 2001 - Aug 2012)

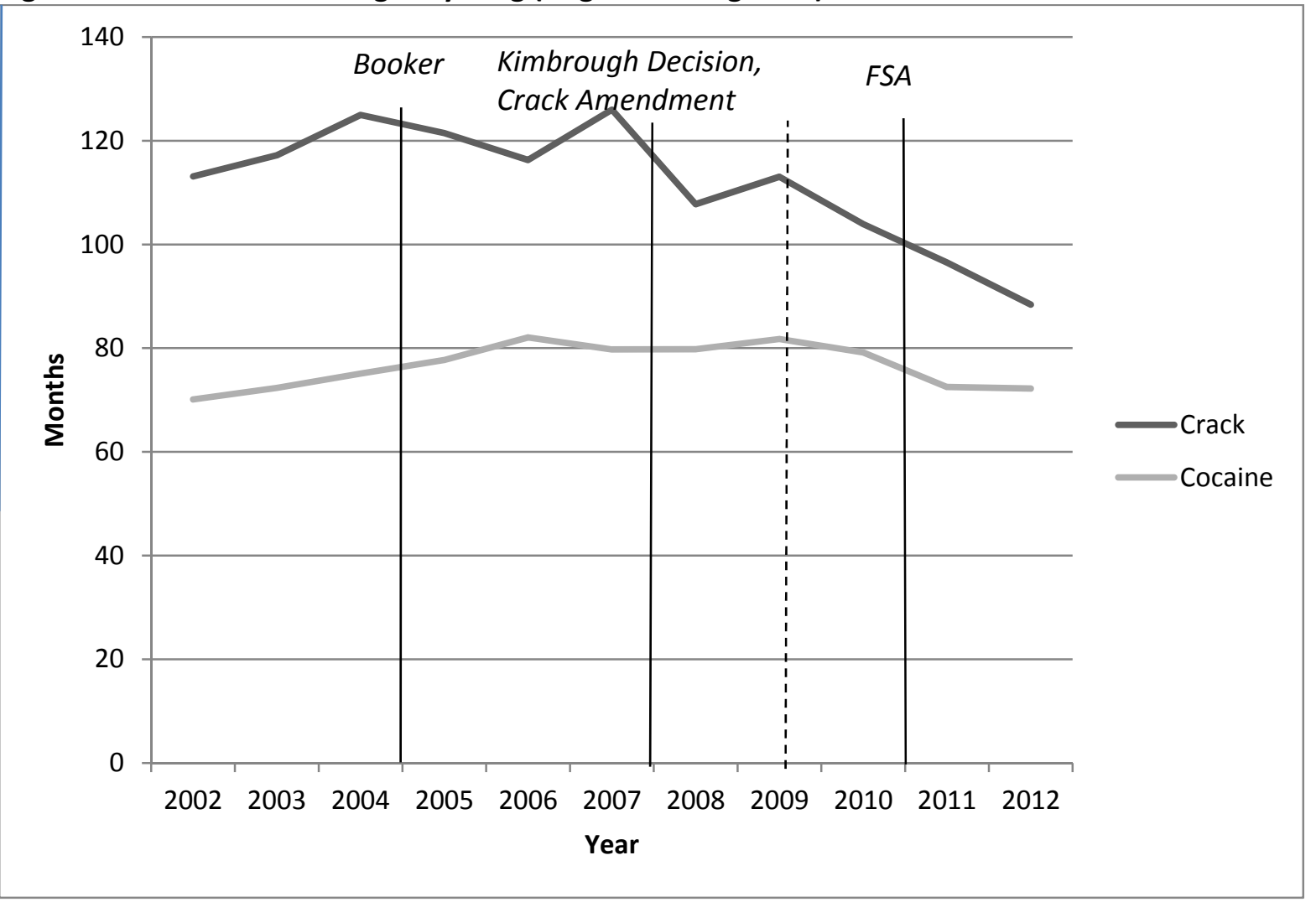


Table 6a: OLS Analysis for Trend Breaks in Sentencing for Crack since 2002 (Dependent Variable - Sentencing Length in Months)

\begin{tabular}{|c|c|c|c|}
\hline & & pecification & \\
\hline & $(1)$ & $(2)$ & (3) \\
\hline PostYear 2003 indicator & 1.92 & 1.19 & 1.41 \\
\hline & (2.308) & $(1.713)$ & $(1.586)$ \\
\hline PostYear 2004 indicator & $10.77^{* *}$ & 5.91 & 5.73 \\
\hline & $(2.228)$ & $(1.654)$ & (2.157) \\
\hline PostYear 2005 indicator & $-4.21 * * *$ & $-3.35 * * *$ & $-2.63 * *$ \\
\hline & $(2.269)$ & $(1.684)$ & $(2.230)$ \\
\hline PostYear 2006 indicator & -5.16 & -0.80 & -0.42 \\
\hline & (2.210) & $(1.641)$ & $(2.270)$ \\
\hline PostYear 2007 indicator & $9.70 * * *$ & $4.08^{*}$ & 2.53 \\
\hline & $(2.181)$ & $(1.618)$ & $(1.671)$ \\
\hline PostYear 2008 indicator & $-18.23 * * *$ & $-13.09 * * *$ & $-12.10 * * *$ \\
\hline & $(2.160)$ & $(1.603)$ & $(2.180)$ \\
\hline PostYear 2009 indicator & $5.27 * * *$ & $-2.71 * * *$ & $-2.36 * *$ \\
\hline & $(2.196)$ & $(1.630)$ & $(2.164)$ \\
\hline PostYear 2010 indicator & $-9.13 * * *$ & $-8.94 * * *$ & $-9.48^{*}$ \\
\hline & $(2.359)$ & $(1.750)$ & $(2.365)$ \\
\hline PostYear 2011 indicator & -7.40 & -9.08 & -7.96 \\
\hline & (2.511) & $(1.863)$ & $(2.291)$ \\
\hline PostYear 2012 indicator & -8.13 & -10.48 & -10.13 \\
\hline & $(2.742)$ & (2.035) & $(2.095)$ \\
\hline race and gender indicators & no & yes & yes \\
\hline crim. history category indicators & no & yes & yes \\
\hline quantity & no & yes & yes \\
\hline (by guideline cell) & & & \\
\hline $\begin{array}{l}\text { two-way clustered standard } \\
\text { errors by district and month }\end{array}$ & no & no & yes \\
\hline
\end{tabular}


Notes: Crack cases only. PostYear $\mathrm{X}$ refers to a dummy equaling 1 if the case was sentenced in or after year X. Standard errors in parentheses. Asterisks indicate statistical significance of chi-squared test of null hypothesis of equality of coefficients between PostYear j and PostYear j-1 (* indicating 10 percent level, $* *$ indicating 5 percent level, $* * *$ indicating 1 percent level). 


\section{Table 6b: OLS Analysis for Trend Breaks in Sentencing for Powder Cocaine \\ Since 2002 (Dependent Variable - Sentencing Length in Months)}

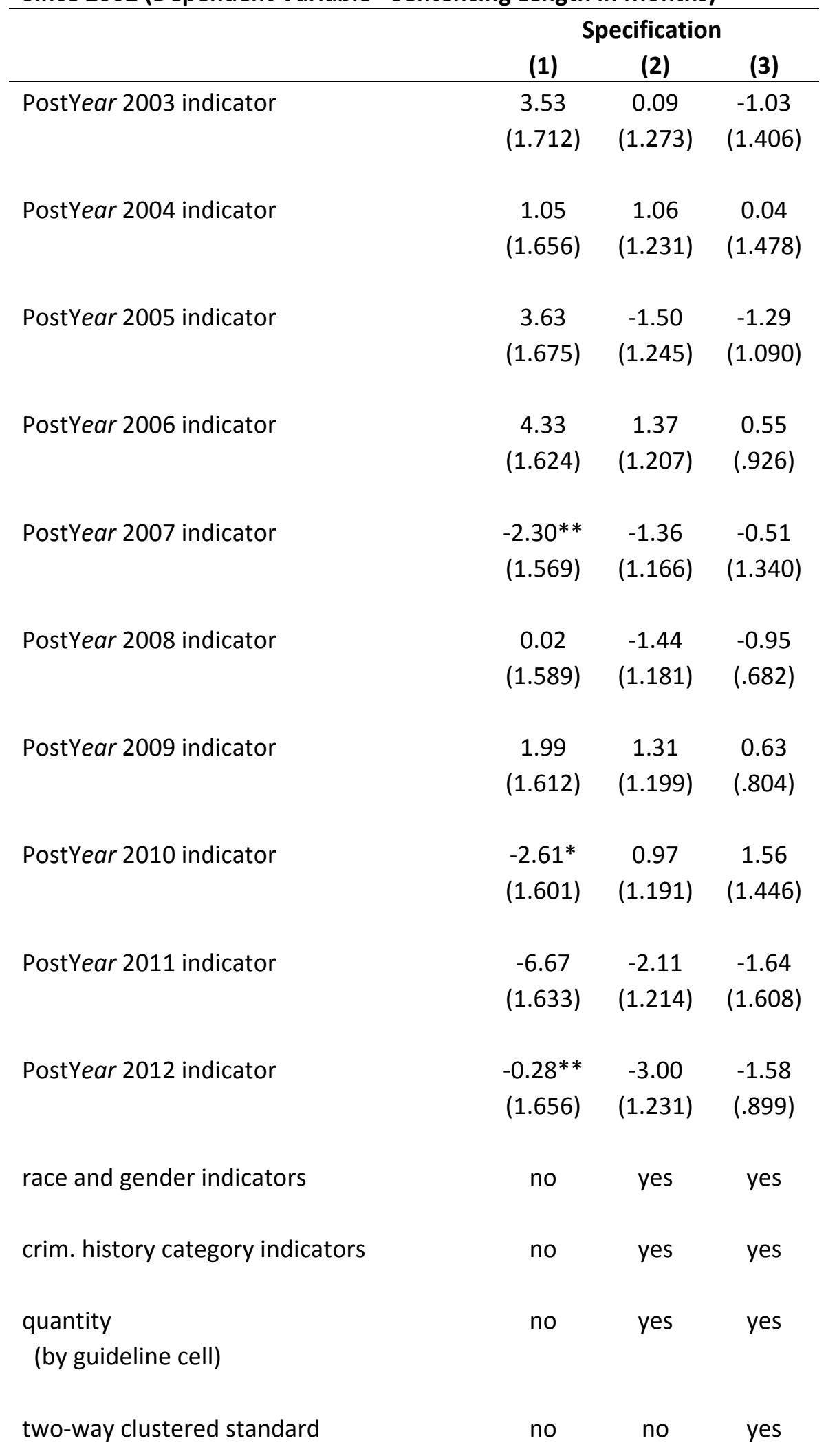


errors by district and month

Notes: Powder cocaine cases only. PostYear $\mathrm{X}$ refers to a dummy equaling 1 if the case was sentenced in or after year X. Standard errors in parentheses. Asterisks indicate statistical significance of chi-squared test of null hypothesis of equality of coefficients between PostYear $j$ and PostYear j-1 (* indicating 10 percent level, **indicating 5 percent level, $* * *$ indicating 1 percent level). 
Figure 4: Distribution of crack conviction quantities by year

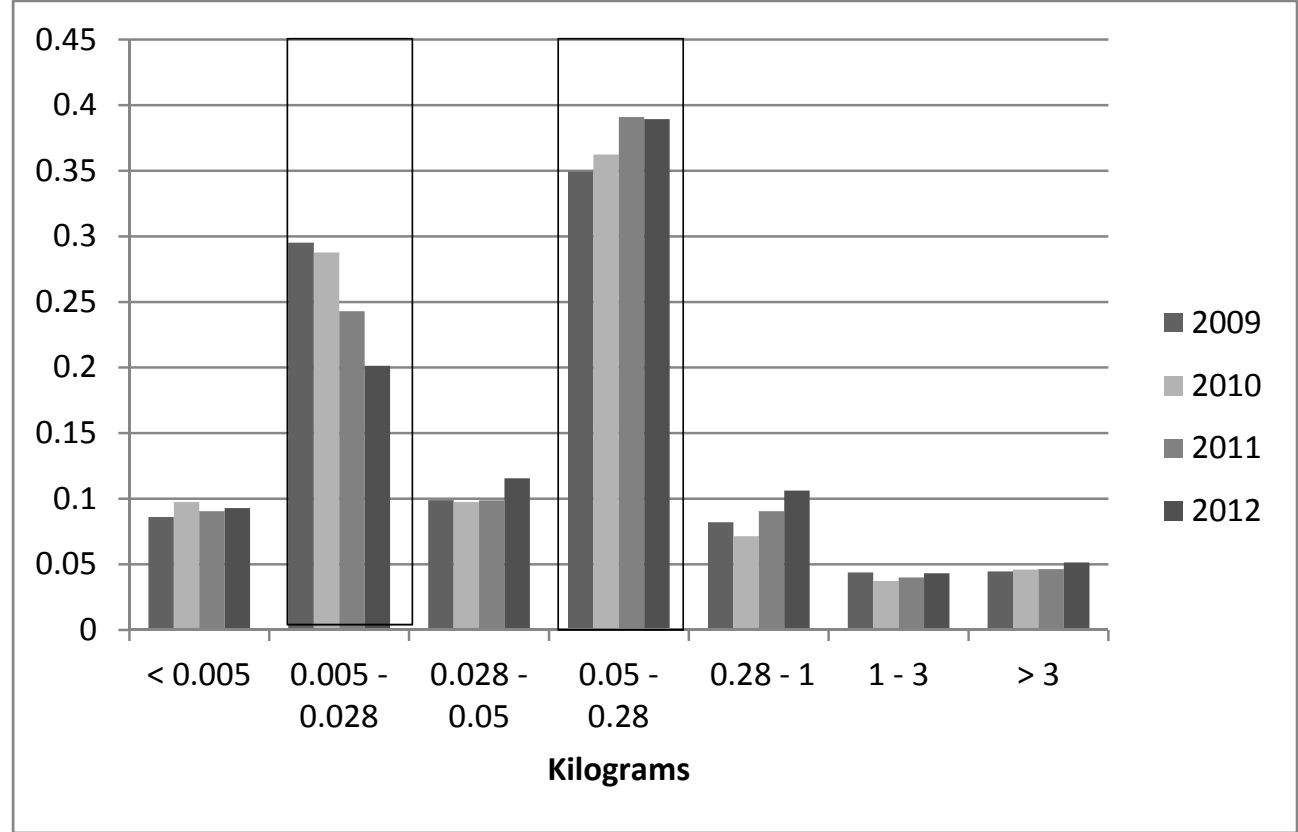

Notes: "Pre-FSA" spans Year 2009 - Year 2010 (i.e., August 1, 2008 - July 31, 2010), "Post-FSA" spans Year 2009 - Year 2010 (i.e., August 1, 2010 - July 31, 2012). Boxes highlight FSA Affected quantities. 
Figure 5: Fraction of crack convictions with safety-valve invoked

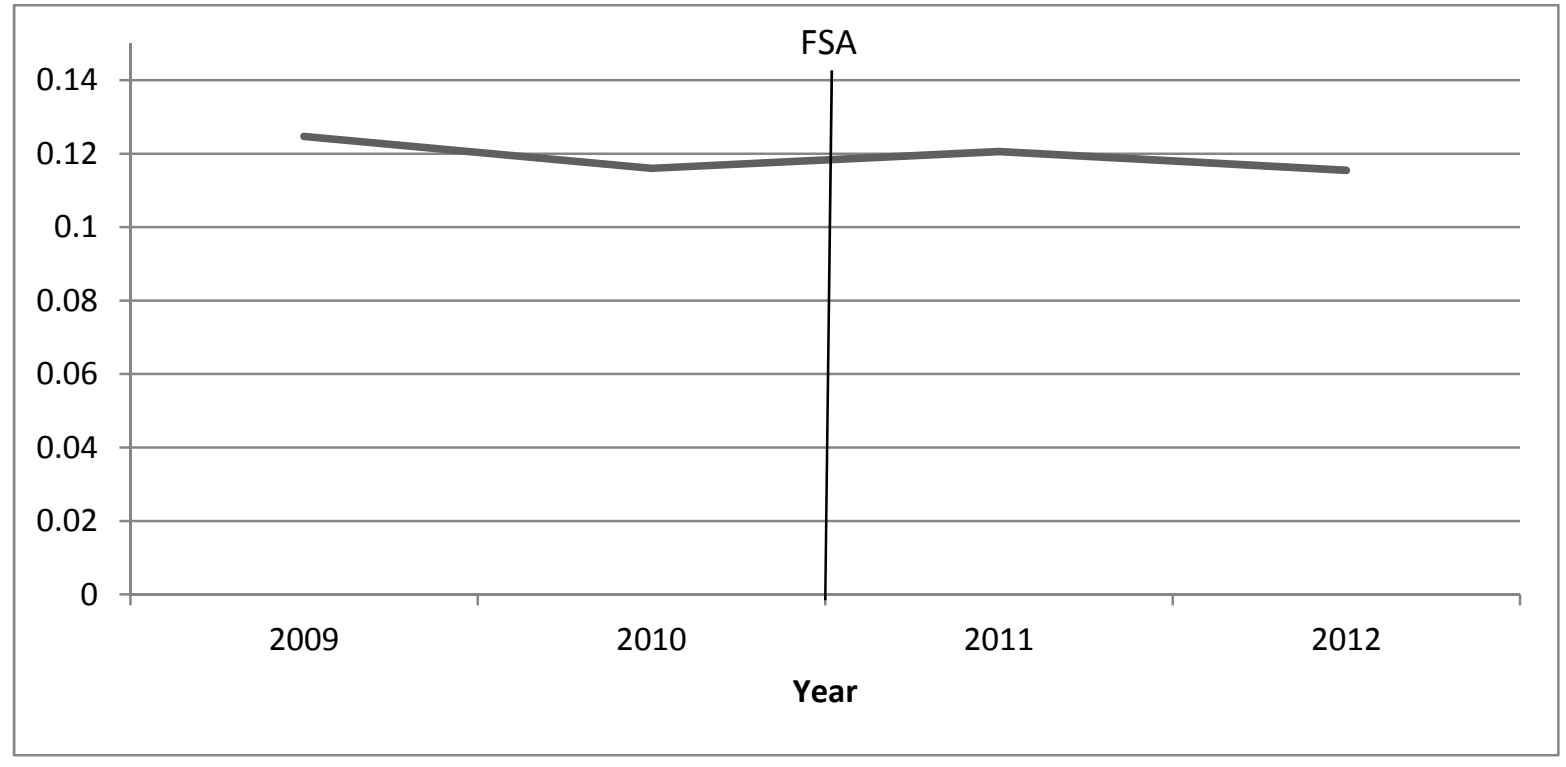

Table 7: OLS Analysis for Trend Break Following Fair Sentencing Act of 2010

(Dependent Variable - Binary Variable for Invocation of Safety-Valve)

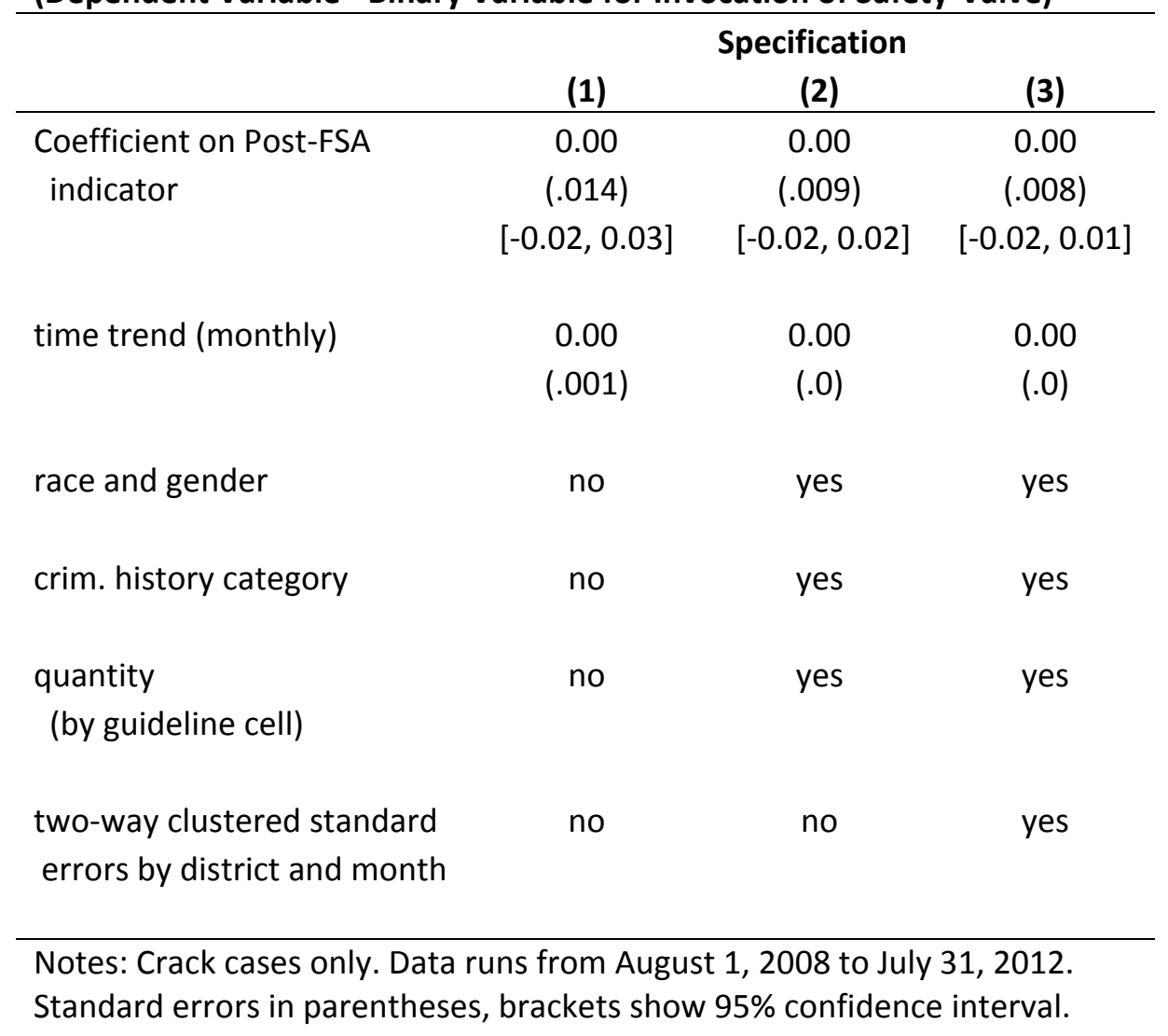


Figure 6: Actual and "counterfactual" mean sentence lengths for crack

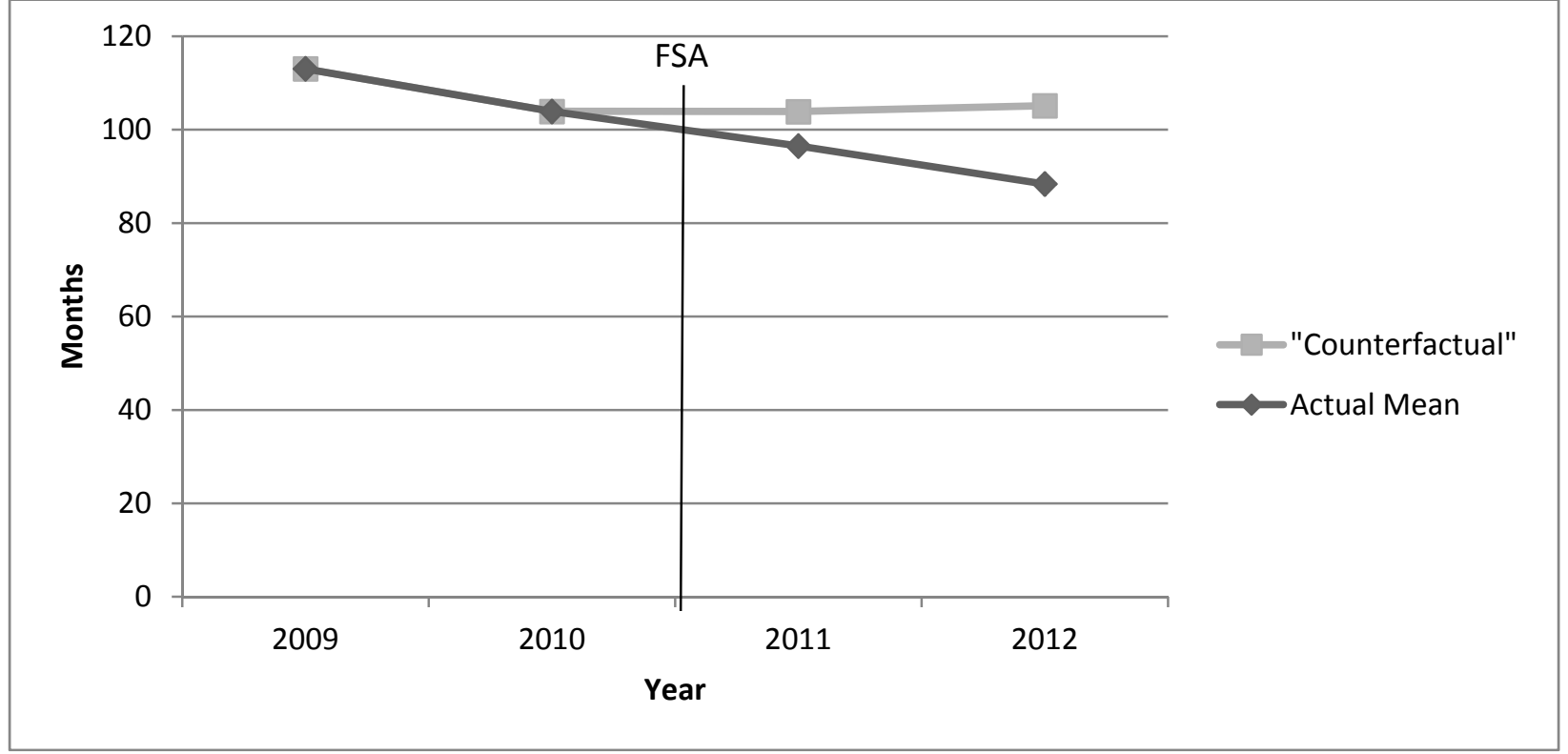

Figure 7: Ratio of mean sentence for crack vs. powder cocaine (<3kg)

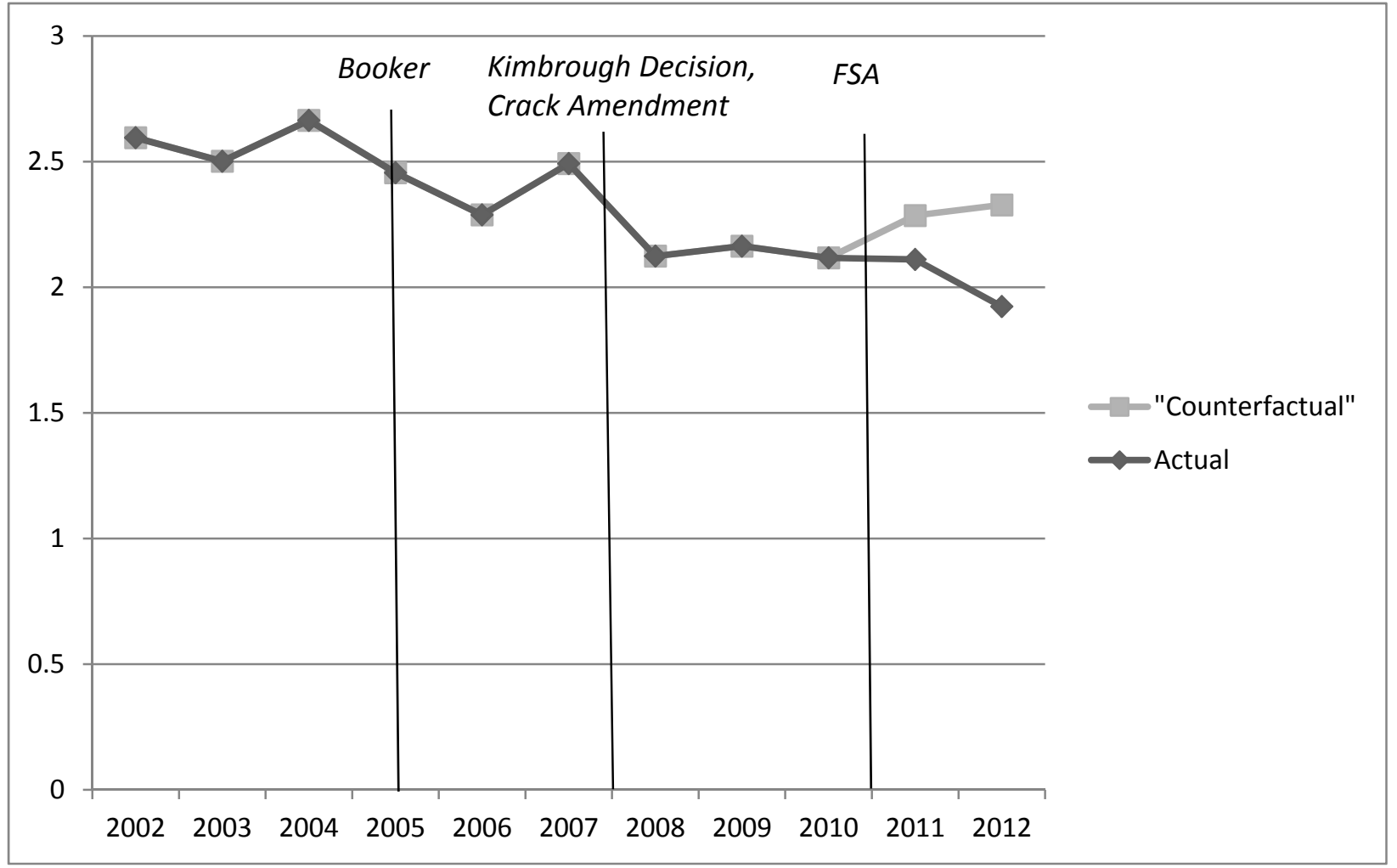

